Portland State University

PDXScholar

$1-1-1983$

\title{
Role conflict and role ambiguity and their perceived relationships to substitute teaching effectiveness
}

Castilla Jack Ryan

Portland State University

Follow this and additional works at: https://pdxscholar.library.pdx.edu/open_access_etds Let us know how access to this document benefits you.

\section{Recommended Citation}

Ryan, Castilla Jack, "Role conflict and role ambiguity and their perceived relationships to substitute teaching effectiveness" (1983). Dissertations and Theses. Paper 517.

https://doi.org/10.15760/etd.517

This Dissertation is brought to you for free and open access. It has been accepted for inclusion in Dissertations and Theses by an authorized administrator of PDXScholar. Please contact us if we can make this document more accessible: pdxscholar@pdx.edu. 


\title{
ROLE CONFLICT AND ROLE AMBIGUITY AND THEIR \\ PERCEIVED REIATIONSHIPS TO \\ SUBSTITUTE TEACHING EFFECTIVENESS
}

by

CASTIIIA JACK RYAN

A dissertation submitted in partial fulfillment of the requirements for the degree of

\author{
DOCTOR OF PHTIOSOPHY \\ in \\ URBAN STUDIES
}

Portland State University

1983 
TO THE OFFICE OF GRADUATE STUDIES AND RESEARCH:

The members of the Committee approve the dissertation of

Castilla J. Ryan presented July 15, 1983.
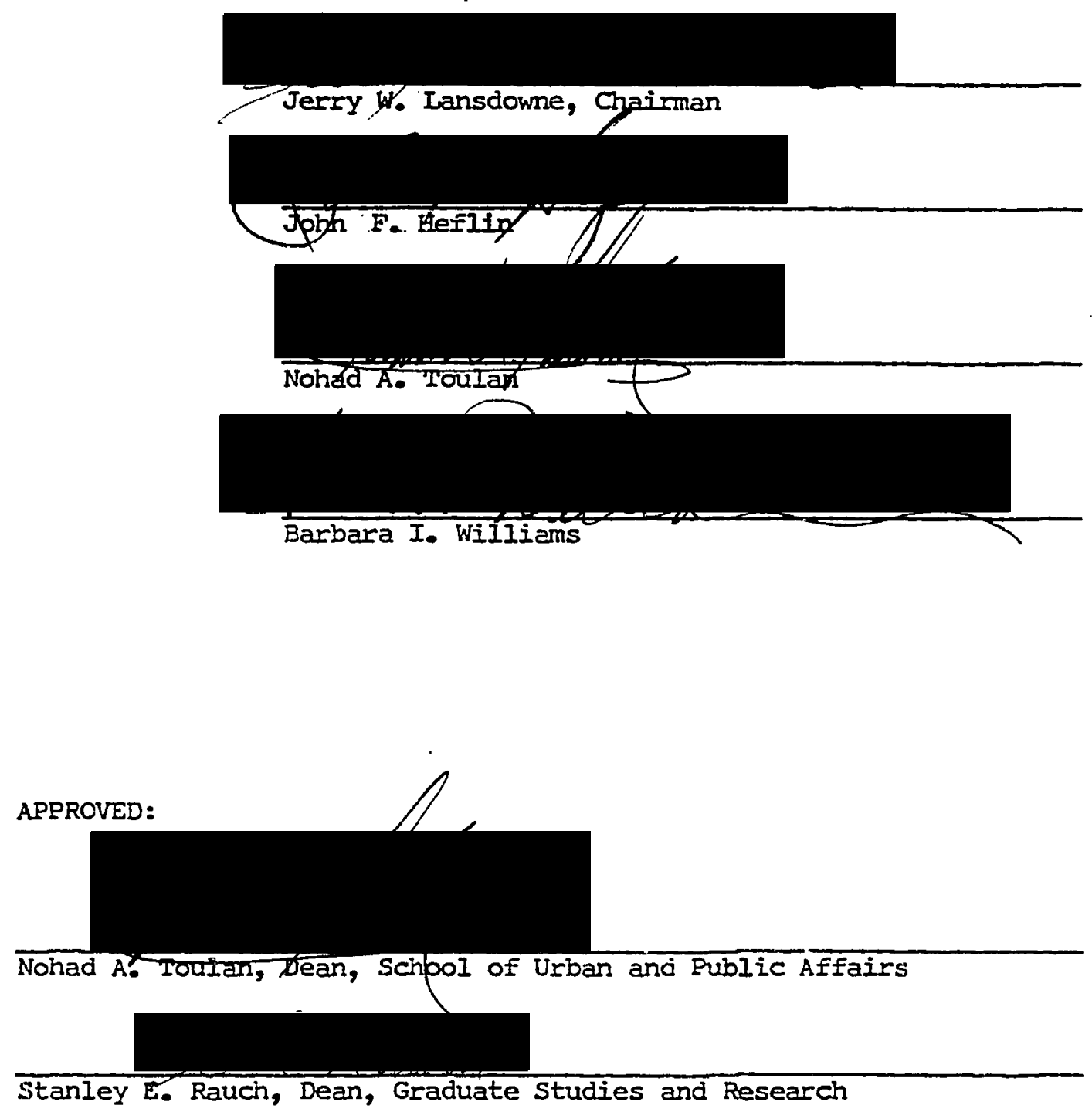
AN ABSTRACT OF THE DISSERTATION OF Castilla Jack Ryan for the Doctor of Philosophy in Urban Studies presented July 15, 1983.

Title: Role Conflict and Role Ambiguity and Their Relationships to Effectiveness in the Substitute Teaching Services

APPROVED BY MEMBERS OF THE DISSERTATION COMMITTEE:

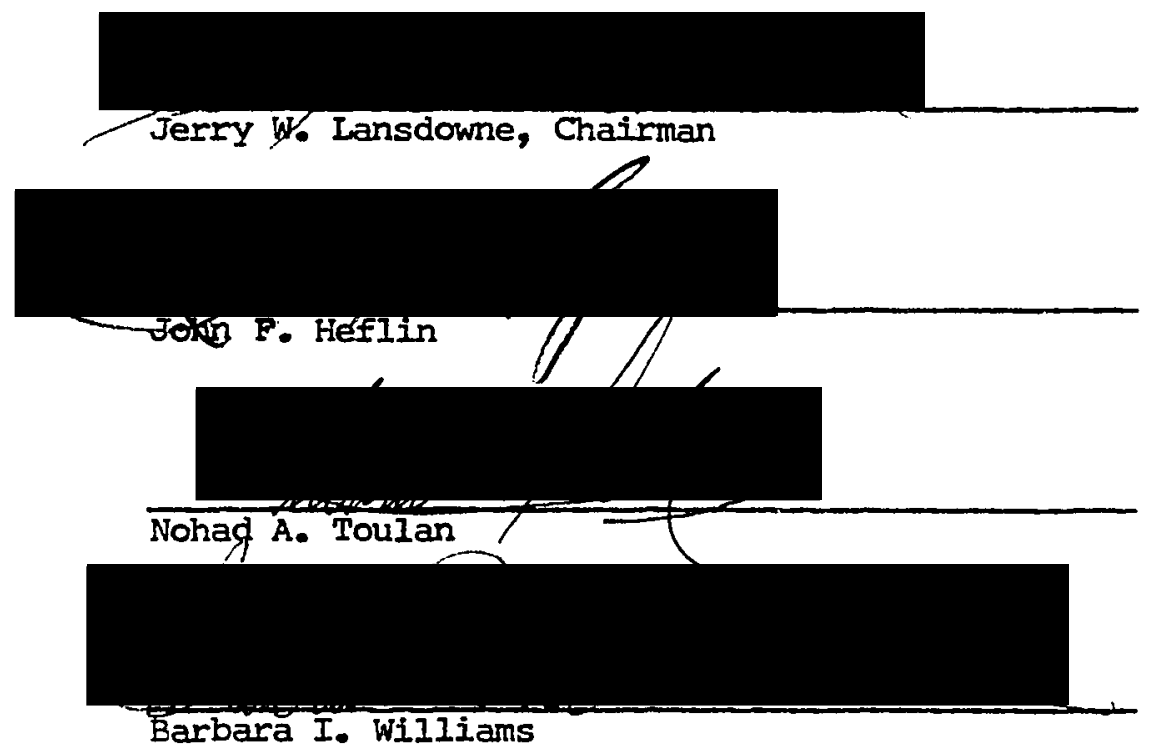

This research is an exploratory study of role conflict and role ambiguity and their relationships to effectiveness in the substitute teaching services. In many public school systems, large numbers of substitute teachers are assigned to a classroom on a daily basis when the regular teacher is absent. The assignment is usually done through a central administrative office. Substitutes are assigned with very short notice; and since their assignment is based on availability, they may be asked to teach a subject outside their certified field. In addition, the lesson plans left for the substitutes by regular teachers may be incomplete or too complex. These situations prevent 
the school district's goal of instructional continuity from materializing. Thus, some studies have shown substitute teachers to be ineffective in the classroom because they were unable to effect the continuity principle. These studies, however, do not show the relationship between role clarity and effectiveness.

This research uses role theory as a framework in which to examine the perfornance of substitute teachers. The literature suggests that role conflict/ambiguity may be related to certain personal and behavioral outcomes. Conceptual models have also shown other indirect factors that may influence the final performance outcome.

The primary question of this research was what needs to be done to improve the substitute teaching services. Specific questions include: (I) To what extent, if any, is there an inter-sender role conflict? Do regular teachers and administrators have a common view regarding the role of the substitute teacher? (2) According to administrators, regul,ar teachers, and substitute teachers, is there role ambiguity regarding the work of substitute teachers? (3) According to administrators, regular teachers and substitute teachers, how effective are substitute teachers at specified tasks? Hypotheses were also tested to determine the relationship between role ambiguity and effectiveness, and the relationship between the socio-economic status of the work-place and the perceived performance.

Data $o_{i}$ the perceived role, and effectiveness $c_{i}$ substitute teachers were collected by random sampling from three groups of educators in two socio-economic areas in the city. ANOVA was used to compare role ambiguity and role conflict. A constructed effectiveness scale gave a 
reliability coefficient alpha of .82. Pearson correlations were also used to test hypotheses.

The results show a negative relationship between role ambiguity and substitute teacher effectiveness. However, there was no role conflict among the three groups of educators tested, nor did the socio-economic status of the work-place make any difference in their perception of the substitute teaching services. 


\section{ACKNOWLEDGEMENTS}

During this long and tedious effort to complete this dissertation, I received support and direction from many individuals. I wish to thank them all for their assistance and encouragement.

Thanks to the members of my committee, Jerry W. Lansdowne, John F. Heflin, Nohad A. Toulan and Barbara I. Williams, who insisted that I do a thorough job. They all helped to keep me honest and on track.

Thanks to Dr. Barbara Stewart and Dr. Victor Doherty who worked with me in the early phases of the research in helping me to develop the instrument. Thanks also to the Portland Public Schools for allowing me to do the research in the schools, and to the administrators and their staffs who responded to the questionnaire.

Thanks to Dr. Marilyn Peterson and Marie Beaudet for their considerable help with the computer work, and to Betty Fox for typing and re-typing the manuscript.

My special thanks to my wife, Patricia, who for the past three and a half years has sacrificed time, money and labor to see me bring this project to a satisfying conclusion. She shares in this accomplishment.

All the achievements of this study I share with my friends, family and advisors; the responsibility for its weaknesses, I alone assume. 


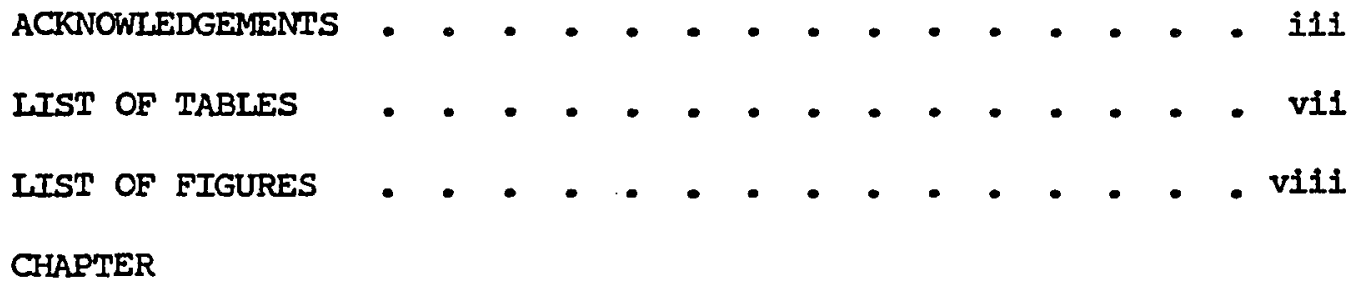

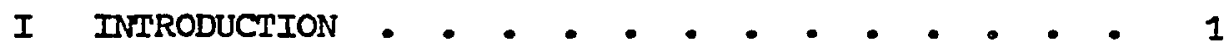

Overview of the Research Problem - . . . . 1

Role Conflict

Role Ambiguity

Concepts of Effectiveness

Socio-economic Influence

Current Research Problem • . - . . - 8

Objectives

Hypotheses

Significance of the study . . . . . . 10

Contribution to Urban Education

Contribution to Educational Practice

Specific Contributions

Limitations - • • • • • • • • 16

Definition of Terms . . . . . . . . 16

Assumptions • • • • • • • • • • • 18

Organization of the Dissertation . . . . 19

II IITERATURE REVIEW AND CONCEPTUAL FRAMEWORK • • 20

Role Episode Model • • • • • • • • • 22

Role Theory - • • • • • • • • • • - 27

Role Definition

Role Conflict

Role Ambiguity 
Other Factors Affecting the Model . . . . 39

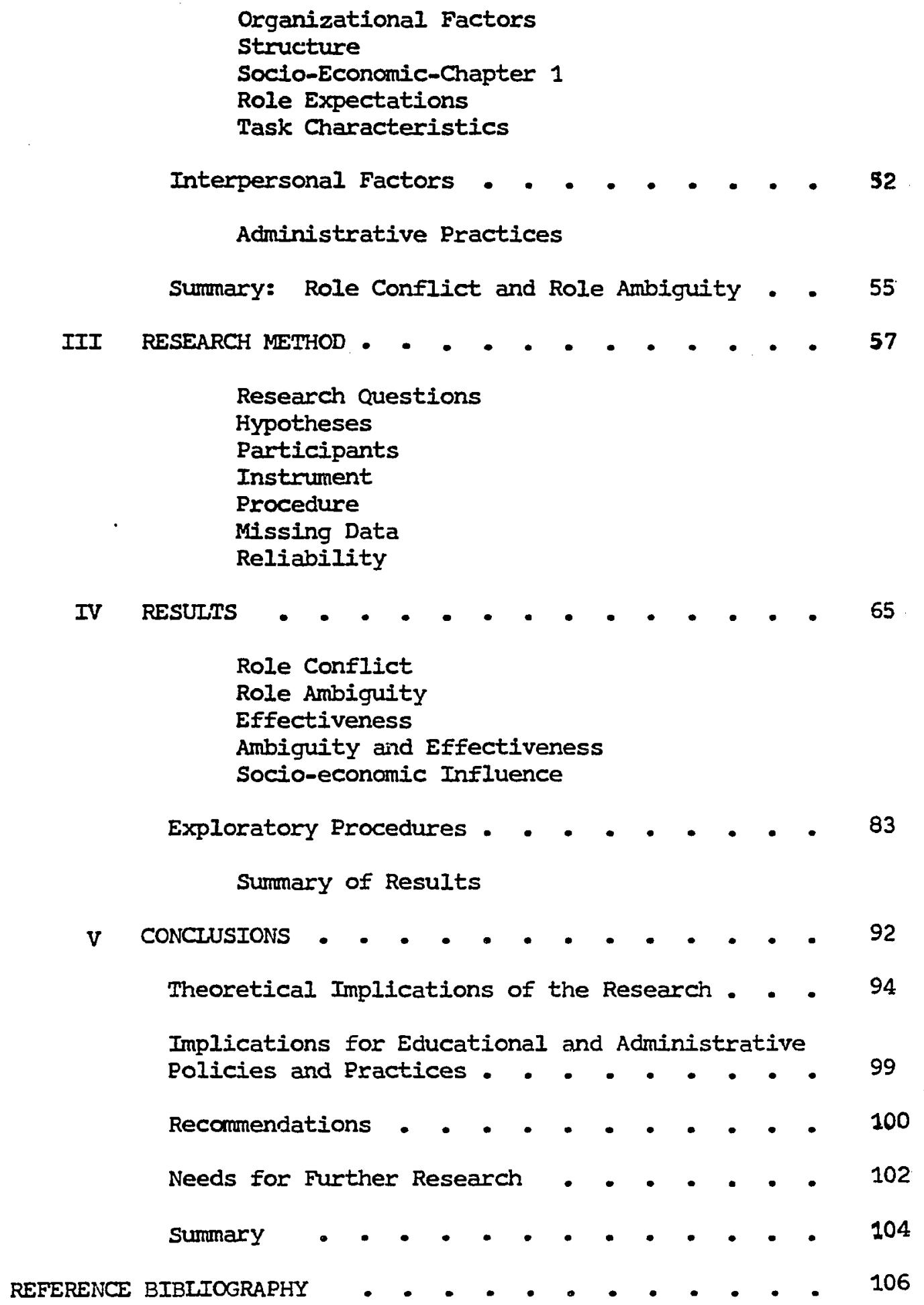


APPENDIX

A LETTER REQUESTING HIGH SCHOOL PARTICIPATION IN THE STUDY • • • • • • • • • • • • • • 111

B COVER LETTER ENCIOSED WITH SURVEY PACKETS • • • 113

C INSTRUCTIONS FOR COMPLETING QUESTIONNAIRE . • • 115

D QUESTIONNAIRE • • • . . . . . . . . . 117

E LETTER OF REMINDER TO EDUCATORS WHO DID NOT RETURN QUESTIONNAIRE WITHIN TWO WEEKS • • • • • • 124

F IETTER OF INTRODUCTION TO THE PORTLAND PUBLIC SCHOOIS • . . . . . . . . . . 125

G IETTER FROM PORTLAND PUBLIC SCHOOLS ENDORSING THE STUDY • • • • • • • • • • . • • 127 
I Number and Percent of Questionnaires Distributed and Returned . . . . . . . . . . . . .63

II Focal Person vs Role-senders Conflict as Reported by Administrators, Regular Teachers and Substitute Teachers 67

III Substitute Teachers' Role Definition - Ambiguity as Reported by Three Role Types: Administrators, Regular Teachers, Substitute Teachers . . . . . . . 72

IV Substitute Teachers' Effectiveness as Reported by Three Role Types: Administrators, Regular Teachers, and Teachers . . . . . . . . . . . . . 74

$v$ Correlations of Substitute Teachers' Role Ambiguity With Their Effectiveness: Substitute Teachers' Perspective . . . . . . . . . . . . 76

VI Perceived Effectiveness of Substitute Teachers by Type of Educator and Location of School . . . . . . 80

VII Correlations of Administrative Practices With Substitute Teachers' Effectiveness . . . . . . . . . 85

VIII Comparison of Means, Standard Deviations, and T-Values for Items Related to Administrative Practices - Ideal and Actual 


\section{IIST OF FIGURES}

EIGURE

PAGE

1 The Role Episode Model - - - - . - - . - 21

2 Extent of Agreement with statements defining role of substitute teachers - • - • • • • • 68 
CHAPTER I

\section{INTRODUCTION}

OVERVIEW OF THE RESEARCH PROBLEM

When a regular classroom teacher is absent on a given day, a qualified substitute teacher must be secured to ensure that the education of students proceeds with a minimum of interruption. Staffing the classroom with temporary replacement is vital to adninistrators whose responsibility it is to provide quality in education, and to regular teachers who are responsible for students' instruction throughout the year.

The substitute teaching services, such as recruiting, training, assigning, supervising, and evaluating of substitute teachers have been relatively neglected in ecucation research, but those studies that are avallable suggest that substitute teachers are not very effective in the classroom. Effectiveness is defined as the substitute teacher's ablilty to provide instructional continuity when the regular teacher is absent (Manlove \& Elllot, 1979; 0lson 1971). However, the substitute teachers' responses to the charges of ineffectiveness indicate that there are certain organizational and Interpersonal problems related to the alleged ineffectiveness (Wotherspoon, 1977). For example, research has suggested that substitute teachers require, among other things, that the following situations be improved:

(a) the lesson plans left by regular teachers, 
(b) the length of notice to report for an assignment,

(c) information on students,

(d) Information regarding the rules and regulations of the school. (NEA Research Bulletin, 1955)

In addition, the literature has suggested that substitute teachers in general are well prepared academically, and, in many cases, have adequate experience for the job. These combined factors - the concerns expressed by substitute teachers for improved communication, and the findings of literature research regarding the qualifications of substitute teachers, - suggest that there could be more fundamental problems influencing substitute teachers' effectiveness. This may include the fellowing:

(a) role conflict - this refers to lack of clarity of substitute teachers' role;

(b) role ambiguity - lack of information regarding expectations associated with a role, and the methods of fulfiling known role expectations;

(c) concepts of effectiveness - the tasks substitute teachers perform and the means used to evaluate those tasks;

(d) socio-economic status of the workplace - that is, the possible influence of low income areas on the perceptions of educators.

Each issue will be addressed briefly and separately in order to develop a theoretical framework for the research, and to give the reader some idea of the extent to which these variables are related to the study.

\section{Role Conflict}

A major hypothesis of this study is that there is confusion about what substitute teachers are to do in the classroom when the regular teacher is absent. The role of the substitute teacher is not 
clearly defined. "Role' can be defined as a set of expectations applied to the incumbent of a particular position by the incumbent and by role senders within and beyond an organization's boundaries" (Van Sell, Brlef, \& Schuler, 1981, p.43). In cextain instances, the incumbent personalizes and individualizes the position so much that individuals in the same position will behave very differently. People fill a role as they percelve 1t, and even change that perception of the role from time to time (Carr \& Ryan, 1974). Additionally, the single or multiple roles wilch confront the individual may not be clearly specified in terms of behaviors or performance level expected; these multiple roles may even require mutually exclusive or contradictory behaviors. Such a situation is referred to as role ambigulty (Kahn, Wolfe, Quinn, Snoek, and Rosenthal, 1964).

Role conflict has been defined as the incongruity of the expectations associated with a role. Kahn et al (1964) has identified the following types of role conflict:

(a) Intra-sender role conflict - incompatible expectations from a single role sender (e.g., a regular teacher):

(b) Inter-sender role conflict - expectations from one role sender which are incompatible with those from another role sender (e.g., regular teacher versus adninistrator);

(c) person-role conflict - Incompatibility between the expectations held by the role incumbent and the expectations otherwise associated with his/her position (e.g., substitute teachers' expectation of what their job consists);

(d) inter-role conflict - role pressures stenming from one position which are incompatible with the role pressures arising from a different position (e.g., substitute teachers may be required to do certain tasks in ane building and quite the opposite in another bullding); 
(e) role overload - expectations upon the role incumbent to engage in several role behaviors, all of which may be mutually compatible in the abstract, but within too short a time period $(e .9$, substitute teachers may be given a short notice to report for an assignment and may be expected to be on time as well as to present a lesson on a difficult subject such as "The Romantic Movement in Iiterature").

Role Ambiguity

Not only is there role conflict, there is also role ambiguity. Role ambiguity has been defined as the degree to which clear information is lacking regarding the following:

(a) the expectations associated with a role;

(b) methods of fulfilling known role expectations; and

(c) the consequences of role performance (Graen, 1976; Kahn et al., 1964).

According to Van Sell (1981), role ambiguity may take one or all of the following forms: (a) information is unclear regarding which potential role expectation - (a), (b) or (c) - should be performed; (b) it is understood that expectation (a) should be met, but information is unclear regarding what behavior will in fact yield (a); and (c) the consequences of behavior (a) are unclear. The significance of examining and interpreting role conflict and role ambiguity lies in their relationship to attitudes, behaviors, and certain psychological conditions affecting the substitute teacher services. Thus, the understanding and improvement of the performance (attitudes and psychological conditions) of substitute teachers is partially dependent upon greater understanding of role conflict and ambiguity.

This study attempts to provide greater understanding of role 
conflict and ambiguity as they relate to substitute teachers within the framewnrk of the role episode model of (Kahn et al., 1964). The model, more fully explained in Chapter II, depicts the interpersonal process between the person being sent expectations (the focal person) and those who are sending the expectations (role senders). In addition, the model incorporates organizational and interpersonal factors which affect the role episode.

The organizational factors include structure, role requirements, task characteristics, environmental characteristics, and organizational practices. The interpersonal factors in the relationship between role senders and focal person include mode of communication, importance of senders to focal person, feedback, and participation between the senders and the focal person.

These factors may affect the role episode, by influencing the role senders, the fecal person, or the relationship between the role senders and the focal person. In this study, however, the main concern is to see how the focal person or substitute teacher is influenced by some of these factors.

\section{Concepts of Effectiveness}

If the role of substitute teachers is unclear, how then can their effectiveness be determined? Effectiveness then becomes a personal assessment based on the individual's interest and perception of the role. It is likely that administrators' perception of the role will be defined by their expectations of the substitute teacher. Similarly, regular teachers will have their own agenda and therefore have their own expectations of substitute teachers. But it is the substitute teachers' concept 
of their role and the feasibility of performing their role that will determine what occurs in the classrocm. when the regular teacher is absent. Effectiveness ${ }^{1}$ as defined by Waldo (1948) is "actual results in comparison to energy expended or to possible results". (p. 201) Accomplishment of a task with the least possible margin between potentiality and actuality is an important consideration in practically all human endeavors. The same is probably true with respect to substitute teaching. If that prerise is accepted, then substitute teachers effectiveness might have to be determined on the basis of:

(a) the amount of time substitute teachers received to go on an assignment;

(b) the subject area they are asked to teach;

(c) 'the students' attitude to learning;

(d) the clarity of lesson plans; and

(e) the extent of administrative guidance and supervision.

The literature indicates a discrepancy between what policy makers and theorists think about efficiency and what the practitioners - teachers - say about it. The former seem concerned with authority, standardization, accountability, and neatly organized evaluative devices (Weber, 1963). The latter, as the following study shows, conceptualize efficiency within the framework of their decision-making ability in the classroom.

In a study done by Porter, Schwille, Floden, and Freeman (1979) to identify potential influences on teacher's decisions about the

1Efficiency or Effectiveness. Both terms are used interchangeably in the literature; they refer to actual results in the classroom in relation to possible results, based upon prevailing classrocm conditions and school district goals. 
content of instruction, taking into account dissemination and accountability pressures, the authors asked the question, "How likely are teachers to supplement tests and textbooks with content that critics would consider more adequate?" This question was addressed in a study based on 20 in-depth interviews with teachers in one school district. The interviews ranged from one to four hours, with most lasting about two hours. The main purpose was to obtain as complete a statement about the content of elementary school mathematics as possible. Teachers were asked what they hoped students in their class would learn and then each of the topics and aspects mentioned was probed for clarification and elaboration.

While the analysis of the interview data showed that teachers varied in their responses, the researchers concluded that teachers' decisions about the content of instruction are an important factor in the learning process. It is, therefore, that ability to decide on content and classroom management on which efficiency is based.

It is important then that this study investigates how educators perceive effectives in the classroom. It is possible that administrators, regular teachers, and substitute teachers have different perceptions of what constitutes effectiveness. A clarification of their concept along with an understanding of role ambiguity and role conflict can provide some insights into the substitute teaching services. Socio-economic Influence

It is also significant to look at the socio-economic areas in which substitute teachers work to see if there is any relationship between the sociomeconomic status of the workplace and the perceptions 
held regarding substitute teachers' effectiveness.

The Portland Public School Chapter 1 Program (formerly Title I) is a complex set of laws, regulations, and procedures aimed at providing "extra" services to educationally disadvantaged students to increase their opportunities for success (Chapter 1 Handbook, 1980). Because such programs demand greater effort and skill from teachers, some education theorists have recommended "incentive pay" for educators who work in urban schools with these students (e.g. Bruno, 1981). Others have recommended "intrinsic rewards" as much more powerful motivators. These include community support, positive social interactions and agreement with district goals (Research Action Brief, \#13, 1980).

This study investigates the relationship between the Chapter I schools and the perceived effectiveness of substitute teachers. In other words, do educators who work in Chapter 1 schools perceive substitute teachers less effective than do educators who work in nonChapter 1 schools? The investigation of this variable helps to explain what potential impact the socio-economic status of the workplace has on the role episode model.

\section{CURRENT RESEARCH PROBLEM}

This study is exploratory and descriptive in nature. It is largely an attempt to clarify some cloudy areas in the substitute teaching services.

This research has the following six main objectives:

(1) to identify the areas of role conflict affecting substitute teachers; 
(2) to identify the extent of role ambiguity experienced by substitute teachers;

(3) to examine the relationship between substitute teachers' role ambiguity and their effectiveness;

(4) to investigate the differences in perceived effectiveness between administrators, regular teachers and substitute teachers;

(5) to evaluate the differences between ideal performance and actual performance as perceived by administrators, regular teachers and substitute teachers; and

(6) to investigate the influence of the socio-economic status of the workplace on the perceptions of substitute teachers' performance.

Specific questions to be answered are the following:

(1) To what extent, if any, is there an inter-sender role conflict? Do regular teachers and administrators have a common view regarding the role of the substitute teacher?

(2) According to administrators, regular teachers, and substitute teachers, is there role ambiguity regarding the work of substitute teachers?

(3) According to administrators, regular teachers and substitute teachers, how effective are substitute teachers at specified tasks?

(4) What is the relationship between the perceptions of educators regarding administrative practices within the substitute teaching services and what is actually done?

(5) What is the relationship between administrative practices and effectiveness?

The following hypotheses arising from these questions will

therefore be tested:

(1) The role expectations held of substitute teachers by regular teachers and administrators are different from those held by the substitute teachers themselves.

(2) The more ambiguously substitute teachers perceive their role, the less effective they will consider themselves in the classroom. 
(3) The performance of substitute teachers in non-Chapter 1 schools is more positively perceived by all groups of educators than that of substitute teachers in Chapter 1 schools.

\section{SIGNIFICANCE OF THE STUDY}

The involvement of substitute teachers in the educational system is quite large. Through the collective bargaining process teachers have gained the right to be absent from the classroom for a variety of reasans. These include absences on account of illness, to attend conferences and seminars for professional growth, for jury trial, for emergencies, funerals and a host of other activities. Unlike other professions, when the regular teachers are absent the clients, the students, cannot be deferred until tomorrow; substitute teachers must take the place of regular teachers to ensure instructional continuity.

"A fact perhaps more startling than indicative, is that in one day (November 30, 1959), California used 14,007 substitute teachers in its public schools" (Nickerson, 1965). This means that $12.5 \%$ of the regular teachers in California were absent on that day for one reason or another.

A research study done at Southern Illinois University indicated that 9,000,000 teachers' days in the nation's public schools were taught by substitutes in 1960-61 (Bear \& Carpenter, 1961). Another study reported that $6 \%$ of the total teaching days, or 10 full days per year, are taught by substitute teachers, and that salaries for substitute teachers are between 2.5\% to $9 \%$ of the total school budget 
of districts across the country (Freednan, 1975). An ERS Report (1977) stated that in 1976-1977 there were 736,696 substitute teachers nationwide on the rosters of school systems enroling 300 or more pupils.

In the state of Oregon, substitute teaching is growing even though public school enrollment is declining. According to the Oregon Substitute Teachers Association (OSTA), there are over 3000 substitute teachers in the state of Oregon and approximately 400 in the Portland district alone. The Statistical Report (1977-1978) of the Portland Public Schools shows that out of an average of 180 work days per school year substitutes were in service 107 days on the average for each year from 1973-1974 to 1977-1978.

Thus, for a substantial part of the year, the education of public school students is entrusted to a large corps of substitute teachers. This corps developed to a great proportion in the 1960's when, fne the first time, there were more qualified teachers than positions available. With greater availability of fully trained and certified teachers, lists of substitutes have grown longer.

However, although thousands of people undertake this duty every day, it has been given very little attention by educational theorists because of its assumed "unimportance" vis-a-vis the problems of the regular classroom teacher.

While the term "accountability" has been associated with almost every segment of the educational profession, for some reason there appears to be less reason to be accountable for high level instruction when the regular teacher is absent (Wotherspoon, 1977).

In view of the central importance of substitute teaching in the 
Iife of the school, it is difficult to understand why this function has not been the subject of sustained study and investigation by educational researchers. Unfortunately, we have available to us little systematic knowledge gained through credible research about the nature of substitute teaching and the variables that influence it. When researchers have given attention to substitute teaching during recent decades, focus has tended to be on survival techniques for the substitute teacher and the scope of substitute teaching. At best, there studies are informational, but they are not very useful in terms of understanding what makes a substitute teacher perform effectively. Clearly, new approaches are needed if we are to gain new knowledge about effective substitute teaching. From the above information, together with the data that indicate that daily teacher absenteeism in the United States averages at least 1 out of 30 (Benthul, 1963), the urgency of obtaining the best possible service from substitute teachers is evident. This is the primary significance of this study.

It is unlikely that the substitute teaching services in general will improve, or that the substitute teachers' performance in particular will change, unless the question of role identification is addressed. An important contribution of this study, therefore, will be the investigation of the role of substitute teachers, and the redefinition of that role within the framework of existing structure arin practice. This role clarification is significant because when the role is clearly defined and understood by all - administrators, teachers, and substitute teachers - better learning, which is the 
MItimate objective of every educational program, can take place in the classroom.

\section{Contribution to Urban Education}

This study was done in an urban center which has all of the problems of urban areas, not least of which are its schools. Although this study does not deal directly with student achievement, such achievement is its ultimate goal. Student absenteeism is known to be the biggest problem in urban schools (NEA Today, April, 1983) and the presence of a substitute teacher in the classroom seems to compiicate that problem (Elliott, 1979). When students are out of the classroom, they are sometimes in the community creating problems for neighbors, businessmen, police, and social workers. But more importantly, since "time on task" is directly related to a student's level of achievement, any improvement in substitute teachers' performance that will keep students "on the task" and subsequently raise their scholastic achievement will be a vital contribution to urban education. (Wiley \& Harnischfeger, 1974).

Further, this study is significant in its contribution to an understanding of the delivery of educational service in urban places. In recent years, urban areas have accounted for more and more of our population. In the decades of the $60^{\prime} \mathrm{s}$ and $70 \mathrm{~s}$, enrollment in urban schools has steadily increased. This shift in population, the large concentration of human, monetary, and other resources in these schools, the cultural, political and social influences of urban centers on the nation, and the problems associated with these factors have raised questions about how schools are organized and how to more effectively 
deliver educational services in urban centers.

Edmund Gordon (1978) has written on urban living and its conse-

quences for education. In his study "toward a Conceptualization of

Urban Education", the author has stressed that there are more critical

problems to urban life than those faced by low status people in our

cities. He suggests that three broad categories which have special

relevance for urban education, are human diversity, human mobility,

and human institutional regidity. He also pointed out that the nation

had increasingly become urban and this urban existence makes the issue

of "critical mass" very important.

Gordon (1978) explains:

One of the greatest problems of an urban society has to do with the establishment, maintenance and the control of the utilization of the mass of resources - whether we talk of human resources or technological resources, a mass that is sufficient to make a difference in the society or to make a difference in the life of a person. Identifying the level of magnitude of the mass necessary to paricular processes and the ways in which that mass may be and needs to be manipulated either to produce effective education or effective health service..., is of critical concern for a nation that has become urban. (p.2)

Thus, this study can help to create an awareness of how our

human and financial resources are used, and can be useful in urban education planning, budgeting, programing and evaluating.

Contribution to Educational Practice

The substitute teaching services are operated on the basis of the availability of personnel to take over the classroom when the regular teacher is absent. This often results in substitutes assigned to a subject area for which they are not academically prepared. This is generally referred to as "misassignment". Misassignment adds to 
the role ambiguity situation by placing substitute teachers in the dubious position of probably knowing what is expected of them but not being able to meet those expectations. Misassignment could then be addressed by applying the findings and recommendations of this study. Some substitutes are also called to serve at very short notice. A combination of misassignment and short notice could be very damaging to the education process. Freedman, (1975) has suggested that calling substitute teachers and asking them at short notice to teach a lesson on the Renaissance is role ambiguity of a high order. The findings of this study could be used to address both practices of misassignment and short notice which appear to be closely linked to role ambiguity. In addition, information about lesson plans, daily schedule and supervision of classes and teachers can be derived from this study, and used to enhance the instructional goals of the education system.

\section{Specific Contributions}

The specific contributions of this study include the following:

(1) Identification of perceived effectiveness characteristics of substitute teachers.

(2) Identification of role conflict/ambiguity of substitute teachers, and its relationship to effectiveness.

(3) An assessment of the level of impact the socio-economic status of the workplace has on the perceptions of the educators with respect to substitute teacher effectiveness.

(4) An appraisal of the administrators role in rpoviding motivation and leadership for substitute teachers. 
ITIITATIONS

It is recognized that the study is limited by the following conditions:

(1) The population from which the sample was drawn is limited to the high school administrators, teachers, and substitute teachers in the Portland Public Schools. The sample size of 149 therefore cannot have universal application.

(2) The body of research on substitute teachers is not very great. This study, therefore, does not have a rich theoretical basis on which to draw.

(3) Some department chair-persons were included in the sample of 53 administrators in order to get a sample big enough for the study. It is believed that although they teach in the classroom, their leadership role could give them a different perspective from the full-time classroom teacher.

(4) This study applies to substitute teachers who are working for a day or two at any given time, and not on a longterm basis.

(5) This study was done at the high school level only.

\section{Definition of Terms}

Some terms used in this investigation are defined below for the purpose of clarification.

Adninistrator. This study is concerned only with administrators at the school level (1.e., principals, vice principals, and department chairpersons).

Regular Teacher. The regular teacher is one under contract to a district to perform the service of teaching a class or classes and who possesses a teaching credential.

Substitute Teacher. The substitute teacher is a guest teacher who assumes the responsibilities of the regular classroom teacher. 
when (s)he is absent. The substitute teacher is sometimes referred to as "substitute".

Short-term. This refers to one or two days of substitute teaching. Instructional Continuity. When a regular teacher is absent, the substitute teacher is expected to follow the lesson plan and the instructional goals of the regular teacher.

Portland School District. This refers to the high schools located in the city of Portland, the county of Multnomah, designated School District Number I.

Targeted Schools. These are schools designated by the federal government's Elementary and Secondary Education Act, Title I, (Education Consolidation Improvement Act of 1981, Chapter 1). These schools are located in economically depressed geographic areas whose median family income falls below a determined level.

In-school Substitution. This refers to an organized system of using either of the following, singly or in cambination:

(a) A substitute program that is organized, developed and evaluated by in-building administrators using a corps of certified substitutes in various capacities as they are needed, including certified and non-certified positions.

(b) Using regular teachers to cover classes in their departments with predetermined compensations.

(c) Any program design that will retain a staff familiar with the school, its program, and students.

Effectiveness. A substitute teacher's ability to provide instructional continuity in the absence of the regular teacher. 
Role Conflict. This is defined as incongruity of the expectations associated with a role.

Role Ambiguity. This is defined as the degree to which clear information is lacking regarding the expectations associated with a role, methods of fulfilling known role expectations, and the consequences of role performance.

\section{ASSUMPTIONS}

The assumptions of this study are:

(a) that the end results of the educative process are largely determined by the effectiveness of classroom personnel;

(b) that it is an appropriate function and responsibility' of the school administration to develop and implement programs of staff development which include all members of the education staff;

(c) that administrators are concerned about the maintenance of a high quality of instruction in their schools;

(d) that the quality of instruction in the absence of the regular teacher is dependent upon the skills, preparation, and professional attitude of the substitute teacher;

(e) that administrators can develop procedures for enhancing the skills of substitute teachers and therefore contribute to the maintenance of academic contimuity in the absence of a regular teacher;

(f). that an effective participant in the educational process has a definite understanding of and an appreciation for his/her role or function as it relates to the goals of the institution. 
ORGANIZATION OF THE DISSERTATION

The remainder of this report includes a more detailed review of the literature on the substitute teaching services and the factors affecting their structure and activities. Particular attention is given to those factors that have a direct or indirect bearing on the role conflict/ambiguity, organizational factors, and interpersonal factors affecting the interpersonal process within the model. Following the review of the literature, the specific research questions and hypotheses to be addressed by this research are presented. This is followed by a discussion of the research design, method, and analysis. Finally, the results of the research are discussed, and the conclusions and implications for policy and practice that can be drawn from it are presented. 


\section{LTTERATURE REVIEW AND CONCEPTUAL FRAMEWORK}

A key concern in this research study is how to make substitute teachers more effective in the classroom. Current evidence from behavioral theory suggests that there is a linkage between performance and clarity of role. In order to establish this linkage regarding the substitute teachers' performance and role perception, it is essential to understand how role conflict and role ambiguity operate, and what are the moderating variables within a conceptual behavioral model.

This chapter seeks to draw on the existing behavioral science theory and research literature to examine these factors influencing substitute teachers' performance. Broadly stated the question to be answered by this review is: which factors prevent or facilitate substitute teachers' effectiveness. However, this review of the literature also seeks to address the organizational and interpersonal issues that may arise relevant to the substitutes' assignment to a classroom on any given day. It is done within the framework of the role episode model (Kahn et all., 1964).

Figure $I$ presents a conceptual model of the factors that are to be discussed in this review. It is presented as a guide to the reader, as this review must draw from a variety of sources. The model is first described, then the relationship of the factors to the role episode model is discussed within the literature review. Those factors appear 


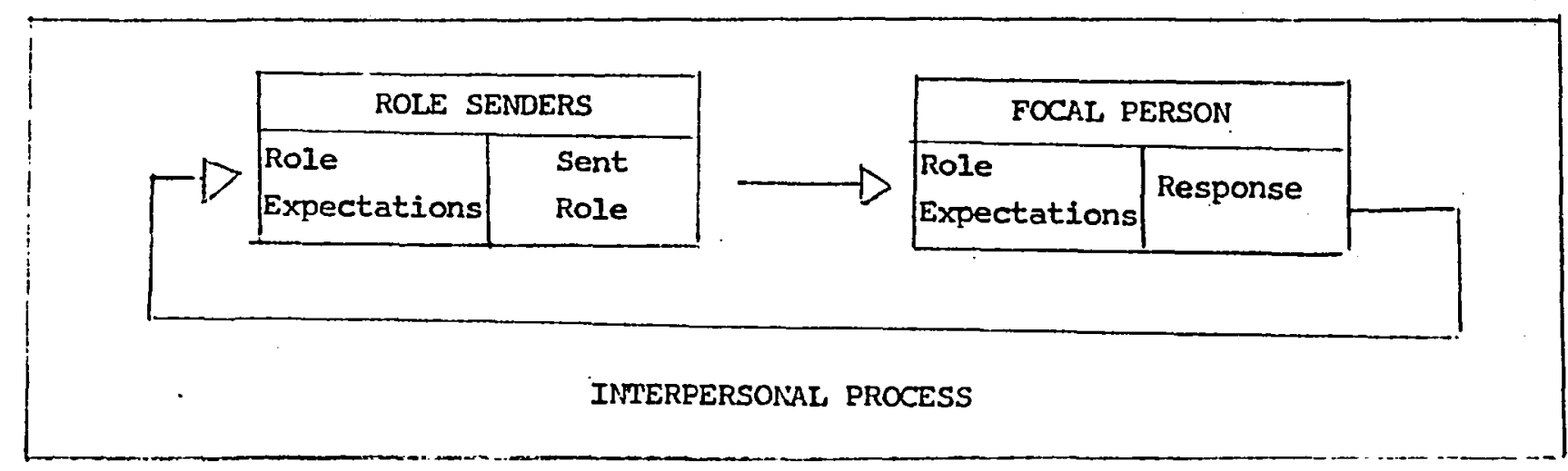

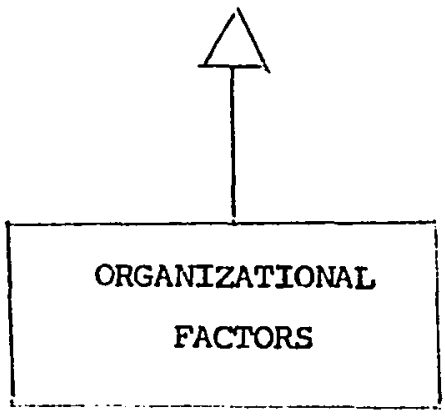

Structure

Role Requirements

Task Characteristics

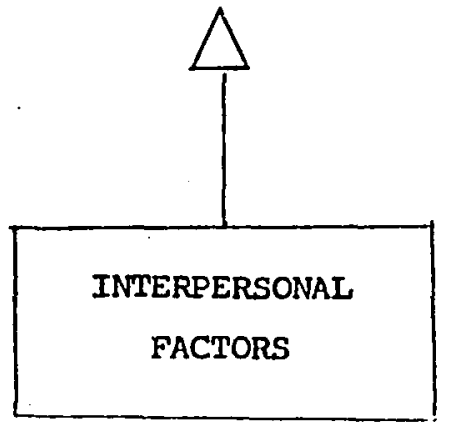

Importance of Sender

Mode of Interaction

Feedback

Participation

Fiqure 1. The Role Episode Model (adapted from Kahn, Wolfe, Snoek, \&Rosenthal, 1964). 
under two general headings:
(a) organizational issues; and
(b) interpersonal issues.

\section{ROLE EPISODE MODEL}

The role episode model is used in this study to integrate the issues of role conflict and role ambiguity. This model was developed by Kahn et al.,(1964) and used by later researchers such as Van Sell et al.,(1981), to show the interpersonal process between the person being sent expectations (the focal person) and those sending the expectations (role senders). The model also incorporates other factors which affect the role episode. These include organizational, personal ${ }^{1}$ : and interpersonal factors.

The organizational factors include structure, role requirements, and task characteristics. The personal factors which can be applied to both the role senders and focal person refer to such variables as an individual's age, sex, and temure in the organization. The interpersonal factors in the relationship between role senders and focal person include importance of sender to focal person, feedback, and participation between the senders and the focal person. The role senders may be the focal person's supervisor or co-workers.

A classic role episode is a complete cycle of role sending, response by the focal person, and the effects of that response on the

${ }^{1}$ Personal factors were omitted from the model presented in Figure 1, as they were not essential to this research. 
role senders. The four boxes represent events that constitute a role episode. The arrows connecting them imply a causal sequence. Role senders have expectations regarding the way in which the focal role should be performed. They also have perceptions regarding the way in which the focal person is actually performing. Kahn et al., (1964) believe that the role senders correlate their expectations and perceptions of the focal person and, further, exert pressures to make his performance congruent with their expectations. "These pressures induce in the focal person an experience which has both perceptual and cognitive properties and which leads in turn to certain adjustive (or maladjustive) responses. The responses of the focal person are observed by those exerting the pressures, and their expectations are correspondingly adjusted. Thus for both the role senders and the focal person, the episode involves experience and response." (p.27)

The literature explains that the episode starts with the existence of a set of role expectations held by role senders about a focal person and his behavior on the job. Although role senders are discussed as a group, it ought to be remembered that each role sender behaves toward the focal person in ways determined by his own expectations, and his own anticipations of the focal person's responses. Under certain circumstances, the role sender, responding to his own immediate experience, expresses his expectations overtly; he attempts to influence the focal person in the direction of greater conformity with his expectations. 
In a sense, the role episode has an element of Pygmalia, and reflects the Pygmalion theory of Rosenthal and Jacobsen (1968).

Pygmalion was a prince in Greek mythology who sculpted a statue of the "ideal woman." So entranced was he with his creation that he fell in love with it. The goddess Aphrodite, hearing of his love, breathed life into the statue so Pygmalion could have his ideal woman.

Centuries later, George Bernard Shaw wrote a play titled Pygmalion, using the theme of transformation. It was centered around Eliza Doolittle, a tattered, ill-mannered Cockney flower girl who became a "lady." The transformation is explained in these words of Eliza, from the Rogers and Hamerstein musical adaptation, My Fair Lady: "The difference between a lady and a flower girl is not how she behaves but how she's treated. I shall always be a flower girl to Professor Higgins because he treats me as a flower girl, but I know I can be a lady to you (Colonel Pickering) because you always treat me as a lady."

These words exemplify the self-fulfilling prophecy, known as the Pygmalion effect; that is, an individual's attitude toward and subsequent treatment of another person have the power to transform that person. The power of expectation can bring about a change in behavior.

But the role episode goes beyond the Pygmalion type of expectation. An expectation can also be defined as an evaluative standard applied to an incumbent of a position. Gross, Mason, and McEachern, (1958), elaborated on this definition and explained that expectation has been 
used in role formulations in at least two different senses. In one, it refers to a prediction as in the case of a statement, "My expectation is that he will arrive at nine o'clock". In the other, it refers to a normative criterion or standard of evaluation: "My expectation is that he should arrive at nine $0^{\prime c l o c k " . ~(p .58) ~}$

Expectation also has a predictive aspect. For example, Sarbin (1951) uses expectation in its predictive sense. He comments that "a position in a social structure is a set of expectations or acquired anticipatory reactions. That is to say, the person learns (a) to expect or anticipate certain actions from other persons, and (b) that others have expectations of him" (Sarbin, 1954, p. 225).

The assumption here is that stability in the prediction of behavior may be of vital importance in the development of evaluative standards. However, what one predicts is not what will necessarily happen. Furthermore, what one predicts is not necessarily what one approves. The prediction of substitute teachers' ineffectiveness is not something welcomed by educators. Thus, Gross et al.,(1958) suggest that for the predictive sense in which the term "expectation" is used, the more general and precise term "anticipation" is preferred. Anticipation denotes statements or feelings with respect to the probability of future events.

Expectation has yet another dimension. Certain expectations may be applied to all incumbents or to a particular incumbent of a specified position. Whether an expectation appilies to all incumbents or to a particular incumbent is dependent on how the position has been specified 
and upon the job description. For example, the job description of a teacher in a Title I school could be different from that of a teacher in a non-Title I school. However, if the position is not specified, though different in character, then the result could be that in concrete interaction situations;, the expectations that one actor holds for a specific incumbent of a position would be in part a function of his relational and situational specifications of this position. In addition, they may be partly a function of his perception of the other positions the incumbent occupies. A case in point might be that one actor may see another as the incumbent of only the position of teacher. Anotiher actor may see the same person as an incumbent of the positions as teacher and black. These different perceptions result in different expectations (Gross, Mason, and McEachern, 1958).

In sum, expectations, as used in the role episode, may refer to evaluative standards. Such evaluations are affected by the complex set of conditions surrounding the behavior of the incumbent or focal person. They may also refer to the sent role to the focal person by the role sender.

Tinus, in the conceptual model presented, the following processes are occuring with respect to substitute teachers' understanding of their role:

(a) Interpersonal Process. Role senders (administrators/ teachers) have certain role expectations of the focal person (the substitute teacher). The role is sent either by the administrator or teacher or both to the substitute teacher. But the substitute teacher has his or her own idea of what the role should be. Based on that 
understanding of the role, the substitute teacher responds in the classroom.

(b) Factors Affecting the Role Episode. The factors affecting the role episode are organizational factors and interpersonal factors. It is postulated that these factors moderate the outcomes of the relationship between a percelved role and a perceived behavior. The result can be role conflict and role ambiguity.

ROLE THEORY

In order to understand role conflict and role ambiguity, it is necessary to first examine the broader subject of role theory. Role theory has its foundation in the writings of Sorokin, Parsons and Merton (Merton, 1976). All three writers have attempted to devise acceptable classifications of the properties and components of social roles. These classifications, they explain, are necessary for the theoretical analysis of "sociological ambivalence". Sociological ambivalence is described by Merton (1976) as perceiving a social role as a dynamic organization of norms and counter norms (Merton, 1976, p.17).

For example, Merton \& Nisbet (1961) points out that there are discrepancles in appraisals of role-performance. These discrepancies are derived from social structures that are variously differentiated into social statuses, roles, and strata, with these having their distinctive (and sometimes opposed) as well as their shared values and interests. This leads us to expect that people occupying different positions in a social structure will tend to differ in their appraisals of the same sicial situations. When this general conception is applied to the particular 
case in point we should find that different criteria of the effectiveness of professional work be employed by professionals and their clients. Laymen tend to appraise professional performance in terms of outcome: . whether it succeeds or fails to solve a problem. Professionals tend to judge performance in terms of what is accomplished in relation to what, under the circumstances, could be accomplished. Thus, unlike the relatives of the deceased, physicians will maintain that the operation was a success but the patient died, just as they will maintain (among themselves) that the operation was botched but the patient survived.

The classification set forth by Pitirim Sorokin (1947) analyses roles and relations as combinations of the following properties: direction of the social relation; its intensity; its duration and, finally, its type of influence (direct or mediated and indirect). The relations between role-partners are analyzed in terms of these variables. He takes the position that social relations are predominantly of one type or another. They combine into three major classifications; these forms are "familistic", (predominantly solidary); mixed (partly solidary, and partly antagonistic), of which contractual relationships are especially typical; compulsory (predominantly antagonistic). Sorokin believes that attention to these dominant attributes of a role or social relation directs us to the function and structure of sociological ambivalence.

Parsons(1951) explains his classification slightly different ly:

Every social role is compounded of either affectivity (norms calling for the ready expression of feeling) or neutrality (non-expression of affect); diffuseness 


\begin{abstract}
(wide-ranging obligations) or specificity (expressly limited obligations); universalism (obligations irrespective of the social status of the other) or particularism (obligations only toward those holding designated statuses); concern with qualities or attributes of the role-partner or with performance; and finally, either self-oriented (the role calling for satisfaction of self-interests) or collectivityoriented (calling for self-interest to be subordinated to the collective interest). (p.67)
\end{abstract}

These abstract aspects of social roles are significant variables that affect the character of social relations, and are the fore-runners of the now developed body of literature known as Role Theory. Clearly, the thrusi of these writings by the theoretical fathers of role theory was to develop a working definition within the context of the social structure. Even the more recent writers have shown a demonstrable difference in their definition of the role concept. The interest the various writers have in "roles" and "role expectations" is to a large degree dependent on their interests and their discipline. The anthropologist, the social psychologist and the sociologist have defined the role concept in relation to the social problem in which they are interested.

Role Definition

Many definitions of the term "role" have been used in the social science literature, representing different disciplines, and different points of view within a single discipline. As a basis for the introduction of role concepts, Iinton (1936) suggests that three separate elements are prerequisites for the existence of a society. These are "an aggregate of individuals, an organized system of patterns by which 
the interrelations and activities of these individuals are controlled, and the esprit de corps which provides motive power for the expression of these patterns". (p.107) Linton seens to perceive the social system as a cultural phenomenon, a sort of guide for behavior. Indeed, the role concept is not treated in isolation, but in conjunction with status, within the context of social relations. A status is simply a collection of rights and duties; a role represents the dynamic aspect of status. When the individual puts the rights and duties into effect, (s)he is performing a role.

Role is also defined in terms of an individual's perception of his situation with reference to his and others' social positions. Sargent (1951), for example, says, "a person's role is a pattern or type of social behavior which seems situationally appropriate to him in terms of the demands and expectations of those in his group." (p.13) While Sargent's definition is culturally based, it also has a personal as well as a situational element.

Gross, Mason and McEachern (1958) have summarized the role concept definitions to reflect the varied interests and disciplines:

(a) a role is a mode of organization of the actor's orientation to the situation.... a sector of the total orientation system of an individual actor which is organized about expectations in relation to a particular interaction context, that is integrated with a particular set of valuestandards which govern interaction with one or more alters in the appropriate complementary roles. (p.13)

(b) a role refers to what actors do as position occupants... How an individual actually performs in a given position, as distinct from how he is supposed to perform, we call his role. 
The role, then, is the manner in which a person actually carries out the requirements of his position. It is the dynamic aspect of status or office and as such is always influenced by factors other than the stipulations of the position itself. (p.14)

(c) quoting Parsons (1956), "a role is what the actor does in his relations with others seen in the context of its functional significance for the social system". (p.15)

The basic idea is that individuals in social locations behave with reference to expectations. Expectations then are presumed by most role theorists to be an essential ingredient in any formula for predicting social behavior.

One of the tasks role theorists set themselves is to account for the variability of the behavior of incumbents of the same position. Gross, Mason and McEachern (1958) have pointed out that all mothers, for example, do not behave in the same manner, and an adequate theory must allow and account for this variability. One theory that is sometimes used to explain this variability is the suggestion that the expectations held for and perceived by actors may be variable. There is also the suggestion that there is usually a common understanding of what the behavior of a position incumbent should be; all differential behavior of position incumbents is therefore accounted for by "the variability in their attitudes, values, personality characteristics or some other phenominon which can be said to intervene between the positional expectation and the role behavior". (P.4)

Gross et al (1958) have also found in trial interviews that actors frequently were exposed to incongruent expectations as incumbents of 
single positions. For example, different school board members had different expectations for their superintendent. Or the teachers and school board had held conflicting expectations for his behaviar as superintendent. This raises questions as to why an actor conforms to one rather than another expectation for his behavior.

The conditions under which expectations are learned or taught and who defines them may be quite variable. Data from interviews with superintencents and school board members support this contention according to Gross et al., (1958).

Consider the following possibilities of variableness:

1. An incumbent of a focal position may define what most of his rights and obligations are and an incumbent of a counter position may accept his definitions.

2. Incumbents of counter positions may define most expectations and an incumbent of the focal position may accept them.

3. An incumbent of the focal position may define his rights while incumbents of the counter position may define his obligations (or their own rights) and both may accept each other's definitions of these role segments.

4. Neither the incumbent of the focal or of the counter position may have well-defined expectations for each other's behavior in their initial interaction and they may be eventually worked out through a trial and error process.

5. Some expectations may be learned prior to, and others during, position incumbency. (p.321)

This suggests that there is no consensus on role definition; the empirical complexities that such lack of consensus creates is enormous. 
Van Sell et al., (1981)defines role as "a set of expectations applied to the incumbent of a particular position by the incumbent and by the role senders within and beyond an organization's boundaries". (p.43) This latter definition related more directly to role conflict and role ambiguity as presented in the current study, and it is to these elements of role theory that this review now turns.

\section{Role Conflict}

There are several ways social scientists differentiate among the problem of role conflict. The first differentiation is to define role conflict according to incompatible expectations perceived by the observer, fron those who define role conflict according to incompatible expectations perceived by the actor (Jacobson, Charters and Iieberman, 1951). The second differentiates those who, in defining role conflict, specify that the actor must occupy two or more social positions simultaneously in order to be exposed to role conflict from those who do not make this specification. The third differentiation is made by Kahn, Wolfe, Quinn, Snoeck and Rosenthal (1964), who define sent role conflict as "the simultaneous occurence of two (or more) sets of pressures such that compliance with one would make more difficult compliance with the other. In the extreme case, compliance with one set of pressures exclude completely the possibility of compliance with the other". (p.19) This latter differentiation is significant for the purpose of the current study. The role conflict in this definition is a fact not only in the environment of the person, but also in his/her internal psychological life. Hence, the role conflict is referred to as 
"objective", or "sent", to distinguish it from experienced or psychological conflict. When therc are two mutually contradictory sets of pressures, one set coming from the supervisors and another set coming from within the position incumbent or focal person the. result is role conflict.

A case in point would be a person's superior who makes it clear that he/she is expected to hold subordinates strictly to company rules and to high production schedules. At the same time, his subordinates may indicate in various ways that they would like loose, relaxed supervision, and that they will make things difficult if they are pushed too hard. The incompatible pressures from above and below create role conflict.

Role conflict is also identified under the following headings by Kahn, Wolfe, Quinn, Snoeck and Rosenthal (1964, pp. 18-20):

(a) Intra-sender role conflict - different prescriptions and prescriptions from a single role sender may be incompatible; for example, when a supervisor requests a man to acquire material which is unavailable through normal channels and at the same time prohibits violation of normal channels.

Within the substitute teaching services a similar type of intrasender conflict may occur when the central office of the substitute teaching services has a stated policy of instructional continuity, that is, substitute teachers must follow the regular teacher's lesson plan, but the office does not give the substitute sufficient time to prepare such a lesson.

(b) Inter-sender role conflict - pressures from one role sender opposes pressures from one or more other senders. The pressures on a foreman for close supervision from his superiors and for looser supervision from his subordinates provide an example of the intersender conflict. 
Inter-sender role conflict within the substitute teaching services may be illustrated by the school principal requiring the substitute teacher to follow the regular teacher's lesson plan, but the regular teacher does not leave a lesson plan for the substitute. There are many reasons why the teacher does not leave a lesson plan for the substitute, but one reason could be that the regular teacher often repeats the lesson on his/her return to the classroom

(c) A third type of conflict is inter-role conflict. Here role pressures stemming from one position are incompatible with pressures arising from a different position. In one school building the substitute teacher may be required to do overtime or take home work, while in another building the substitutes have no such requirements made of them. Inter-role conflict can also be experienced when the focal person has a conflict in meeting the demand of his employer, and at the same time fulfilling his role as a husband or father. Demands from role senders on the job for overtime may conflict with pressures from one's wife to give undivided attention to family affairs during evening hours.

These three types of role conflict are usually referred to as "sent" role conflict. They originate from the role-sender, but will regularly result in psychological conflicts for the focal person. These psychological conflicts express themselves in stress, job dissatisfaction and withdrawal.

(d) A fourth type of conflict is called person-role conflict. It can occur when the role requirements violate moral values. For example, when a middle manager or executive is pressured to engage in price-fixing deals which may be opposed to his personal code of ethics, person-role conflict occurs. In other cases, the substitute teacher for example, may be unable to use the skimpy lesson plan of the regular teacher and feeling bound by conscience or professional honesty to be productive, present a creative lesson on the 
arts. Such behavior may be called into question by the principal for ignoring school rules.

(e) From these four basic types of conflict other complex forms of conflicts scmetimes develop (Kahn et al.,1964). One excamole of this farm of conflict is known as role overload. "Overload could be regarded as an inter-sender conflict in which various role senders may hold quite legitimate expectations that a person perform a wide variety of tasks, all of winich are mutually compatible in the abstract. but it may be virtually impossible for the focal person to complete all of them within given time limits. He is likely to experience overload as a conflict of priorities; he must decide which pressures to comply with and which to hold off." (p.20)

Thus role overload for the substitute teacher may consist of expectations to engage in several role behaviors, all of which may be mutually compatible in the abstract but within too short a period of time. These expectations become mutually contradictory in view of the short notices substitute teachers receive to report for an assignment; they may be also asked to teach outside their field of specialization.

All these types of role conflict exert role pressures to change the behavior of the focal person, in this case the substitute teacher. When these pressures are applied, the focal person who is already behaving as (s)he understands the role must find ways to cope because of the threat to his/her existing equilibrium. Gross et al., (1958) suggest that there are situations involving both legitimate and illegitimate incompatible expectations. The current exploratory study, however, will focus on whether or not there is role conflict within the substitute teaching services and what relationship it has to substitute teaching effectiveness. 
Role Ambiquity

Iike role conflict, defined above, role ambiguity can be thought of as a kind of inadequate role sending. Each member of an organization must have certain kinds of information at his/her disposal if (s)he is to perform a job effectively. Communication process and feedback are closely linked to an organization's effectiveness.

Graen (1976) and Kahn et al.,(1964) have defined role ambiguity as the degree to which clear information is lacking regarding the expectations associated with a role, the methods of fulfilling that role, and the consequences of role performance. But ambiguity is sometimes divided into two distinguished components: objective ambiguity and subjective ambiguity. Objective ambiguity is a condition in the environment; subjective or experienced ambiguity is a state of the person.

Kahn et al., (1964) give the following analogy from the field of meteorology to show the meaning of the distinction between objective and subjective amioguity:

One property of the atmosphere, of concern to airplane pilots among others, is the degree of "visibility." Visibility is described in terms of how well a person with 20-20 vision might be expected to see in a given environment; it is the distance at which he can be expected to make certain visual discriminations. Thus the concept of visibility is ultimately responsebased, but is independent of the visual acuity of any given perceiver. Moreover, in its operational form visibility is not a property of the perceiver at all. It refers instead to the density of moisture and dust particles in the air. Its major importance lies in the extent to which it influences vision, and the measurement of visibility is customarily expressed in terms commensurate with the vision process. (p.22) 
Thus objective ambiguity characterizes certain properties of the social and physical environment in terms of their likely influence on the perceptual and cognitive processes of an individual. Their actual influence on an individual constitutes his subjective ambiguity in that particular situation. Both types of ambiguity speak to the need for information and communication.

In terms of the substitute teaching services, in order for substitute teachers to conform to the role expectations of the role senders and to perform their role adequately certain clear information is required. They need to know their rights, duties and responsibilities within the classroom, within the building and within the system itself. They also need information on how best these activities can be performed; and they need to know the potential consequences of their role performance or lack of performance for themselves, their role senders and the system itself.

Lack of information in an organization can result from many causes. In some cases the required information does not exist. There is no available information in the substitute teaching services under consideration about opportunity for advancement, about which behaviors lead to rewards and which lead to punishment. In other cases existing information is inadequately communicated. When people know what to do, they do not always know how. The result is uncertainty because the expectations defining the role are themselves vague and inconsistent. Another aspect of uncertainty is derived from not knowing whose expectations they are required to meet. When there are conflicting expectations one or more of those expectations are bound to be ignored 
in order to cope with the demands of the job. Here again, available channels of communication become absolutely essential. And since ambiguity increases as objects and events recede in time and space, immediate feedback becomes critical. Thus, for many reasons, information about the work environment, the interpersonal climate, and about the appraisal of one's performance may be as important as knowing the job. It may also be the means of reducing the level of ambiguity. Conflict and ambiguity tend to pose special problems of adjustment for the individual substitute teacher. How each substitute copes with these problems depends on the school system's response as an organization. The substitute's relationship with members of his/her role set (administrators, teachers and students) may also tend to condition his/her reactions to conflict and ambiguity.

OTHER FACTORS AFFECTING THE MODEL

In the conceptual model examined, the role senders and the focal person interact through the process of expectation and response patterns. Role conflict and role ambiguity can result from the impact of the interpersonal process. However, organizational factors and interpersonal factors are also examined to see what influence they might have on the role episode. The organizational factors include structure, role identification, and task characteristics.

Structure. The Portland Public School system operates the substitute teaching service through a central administrative office. One of the advantages of a centralized system is that it coordinates the substitute teacher pool and distributes individual substitute teachers 
to an assigned building with minimum notice. In other words, its main function is to serve as a clearinghouse for the assignment of substitute teachers on short notice.

This arrangement, however, limits the ability of the central office to adequately assess, recruit, develop, monitor, and evaluate substitute teachers and their performance. A further limitation of the centralized system is that it places constraints on the school building administrators some of whom, it is postulated, would be able to initiate an in-building program of selection, training and evaluation of substitute teachers. Hierarchical structure, in the institutional sense, while technically superior over other forms of organization, tends to standardize performance expectations and relies heavily upon the use of general rules to control behavioral outcomes. (Abbott, 1965)

But as Nirenberg (1978) has argued, it is difficult to treat teachers who gravitate toward a high level of autonomy as part of their professional orientation, supported to a certain extent by broad discretionary power of academic freedom, as workers who are managed under an industrial model of management. It is the nature of teachers' autonomous orientation that sometimes comes into conflict with institutional goals, and thereby influences the role episode in an indirect manner. The literature seems to show that perceived environmental variables, such as amount of organizational autonomy, are related to role conflict (Rogers \& Molnar, 1976). 
Socio-Economic Structure

Another facet of the structural arrangement is the division of the school district into Title I and non Title I schools, or schools in low socio-economic areas and those that are not.

This study makes the assumption that substitute teachers who work with disadvantaged children in a low socio-economic area will be rated less effective than those substitutes who work in a middle or upper-class cormunity. This assumption is based on the literature pertaining to the special educational needs of disadvantaged children. During the $1960^{\prime} s$, there were many events designed to create appropriate conditions for equal educational and occupational opportunities. There was a commitment to look at the urban crisis in terms of its educational and occupational and sociological dimensions, and researchers launched a variety of studies to describe disadvantaged populations in urban areas in these various contexts (Passow 1977).

In 1963, Harry Passow wrote and quoted in a later work, "The 1960 census reports indicate that 61.3 percent of the nation's population lives in 189 standard metropolitan areas. From 1950 to 1960, more than 80 percent of the total population increment took place in these areas. For education, the more dramatic fact is that almost one of every six elementary and secondary school children now attends a public school in one of the sixteen largest American cities". (Passow, 1977, p.1)

These statistics underscored the need to address the problems of large urban areas. Out of this concern grew the Ford Foundation's Great Cities School Improvement Project. During the 1960's the Great 
Cities teams tackled such problems as current and prospective youth employment opportunities, and educating an increasing number of children with limited background.

In addition, a Research Council of the Great Cities Program for School Improvement was formed. Its first study dealt with the preand in-service education of teachers, aimed at finding and recommending more effective ways to prepare teachers for the demanding work of teaching children with limited backgrounds. Most of these children were in urban schools (Passow 1977).

It had become apparent by this time that a variety of educational changes were in the making and that the advocates for change were gaining ground. However, Eckstein (1978) has argued that while educational changes are desirable, education should not be considered the panacea for urban flight.

At one time, it was argued that universal schooling could deal with all social inequities, that curriculum change could effectively recuce social evils, and that efforts made in schools could achieve widespread changes in attitudes and practices throughout society. Good schooling could even arrest urban decay and social tension. Even the most committed educators today would agree that such views were over-optimistic. (p.53)

However, educators still persisted in the conviction that changes in school organization and educational practices were needed and that individual students could be turned around. One of the changes that dominated the thinking of legislators, researchers, and educators alike was compensatory education. This is the notion that educational inadequacy is both cause and result, and that large extra infusions of resources may make up for the deficiencies. A comprehensive remedy 
that was applied, consisted of more intensive, personalized approaches to learners, specialized instruction in selected curriculum areas, and a wide range of psysical and psychological support services both for students and their families (Eckstein 1978).

Compensatory education actually materialized as one of the responses to educators and administrators who pointed out the need to move away from human and institutional rigidity.

Gordon (1978) has pointed out that one of the functions of institutions of social control is stability. It is necessary to have stability for efficient management. But stability in the hands of human beings most often gets reflected as rigidity. It is extremely difficult for institutions to be flexible enough to serve the varied interests of diverse populations.

Gordon (1978) cites the following example:

In New York, for instance, there is no lack of understanding in the educational system for the needs of the diverse students in it. But the translation of that understanding into direct services for students, mediated by a bureaucracy that is intent upon protecting itself and protecting that system creates a rigidity in the behavior of that institution that makes it impossible to adequately serve youngsters. (Gordon, Urbanicity and Urban Education, p. II)

The shift from rigidity to flexibility finally expressed itself in another change in urban education with the advent of the Title I program. This is a declaration and policy of the United States government to provide financial assistance to state and local educational agencies to meet special needs of educationally deprived children, on the basis of entitlements calculated under Title I of the Elementary and Secondary Educational Act of 1965. Further, the congress 
recognizes the special educational needs of children of low-income families, and that concentrations of such children in local educational agencies adversely affect their ability to provide educational programs which will meet the needs of such children. (Portland Public Schools Chapter 1 Program, Appendix A).

An updated version of Title $I$ is called Chapter 1 - Financial assistance to Meet Special Educational Needs of Disadvantaged Children. This Public Law of August 13, 1981 contains similar provisions as the Title I program, except that it attempts to "eliminate burdensome, unnecessary, and unproductive paperwork and free the schools of unnecessary federal supervision, direction and control". (Portland Public Schools Chapter 1 Appendix A, p.I)

Some of the features of the Chapter . program include (a) size, scope and quality, (b) parent involvement (c) teacher involvement.

\section{(a) Size, Scope and Quality}

Chapter continues the requirement in Title I that a local educational agency's (IEA) sufficient size, scope, and quality to give reasonable promise of substantial progress toward meeting the special educational needs of students to be served. In designing a program to comply with this requirement a district needs to consider the nature of the problem students are having and their specific needs, and the delivery system available in the particular district for providing the indicated services.

The program is very flexible and often adapts to meet the needs of students. Some students respond better to one-to-one, or very small group situations. The appropriateness of the size of the group may vary dependent upon whether services are provided by a student tutor, an instructional aide, or a certificated teacher who has a wealth of teehniques and a rich background of experience for helping educationally deprived students.

The scope of the program is planned to match the resources available. Normally, the average per pupil expenditure should not be lower than $\$ 450$ per student. 
Chapter I funds are used to help students achieve the basic skills of mathematics, reading and/or basic language arts skills. Sufficient concentration of effort must be applied in the selected subject or subjects to assure a high probability of success for the students. Because of limited resources it is sometimes advisable to limit instruction to a single basic skills area (e.g•, reading).

Instructional time is another variable factor which is indicative of program quality and probability of success. Research indicates a definite correlation between the time spent on direct instruction and student achievement (Wiley and Harnischfeger, 1974).

\section{(b) Consultation With Parents and Teachers}

The law no longer requires formal parent advisory councils but it mentions parent consultation in the design and implementation of programs by the parents of such children. The Congressional Conference Report (Sec. 556 (b)) on Chapter 1 emphasizes that it is the intent of Congress that parent involvement is an important component of the program "... and wish to make clear that it is an option of the local education agencies to continue using Parent Advisory Councils (PACs) to comply with the consultation requirement."

Parent consultation could be accomplished by one or more of the following methods:

(1) Continue with school advisory councils and district advisory council, with the majority of council members being parents of Chapter 1 students.

(2) Continue with district PACs only, with all target schools represented or schools PACs only, a majority of either council being parents of Chapter 1 students.

(3) Include Chapter I parents in the general district advisory council.

(4) Develop an instructional plan for each Chapter 1 student with the parent of each student being consulted in the planning and implementation of the program.

(5) Develop parent volunteer programs to include parents of chapter 1 students and 
consult with these volunteers in the planning and implementation of this program.

(6) Form a Chapter 1 review panel which would include Chapter 1 parents. This panel would be consulted on the design and implementation of the program. (To include, but not be limited to: Evaluation, needs assessment, planning, application, etc.)

These options discussed above are by no means the only ways to meet the parent consultation requirement. They are simply alternatives that IEAs may wish to consider when planning parent consultation. However, they do illustrate the intensity and commitment required for the success of the program.

(c) Teacher Involvement

Teacher involvement and commitment are also required. Under Section 556(b)(3) of Chapter 1, IEAs must also consult with teachers of the children to be served in designing and implementing Chapter 1 projects. However, no particular form of teacher consultation is required. An LEA may wish to hold special staff meetings to discuss the Chapter 1 project, or it may devote portions of regular staff meetings to Chapter 1. As with parent consultation, although only consultation with teachers of the children to be served is required, it is not inconsistent with Chapter 1 to involve all teachers.

Clearly, teachers who work in these situations are much more heavily taxed emotionally and physically. The high standards demanded of the program takes its toll over time. When substitute teachers take the place of regular teachers in one of these schools they enter into a specialized activity. Their success probably depends on how much information they have about the program and how committed they are to teaching disadvantaged students. And the role senders perception of these substitutes may be influenced by the high standards set by the regular teachers. 
Role Expectations of Substitute Teachers

The arrival of the substitute teacher to the classroom all too often symbolizes a holiday to the students; it means freedom from routine, from academic foil, and an occasion to disrupt the education process (Wayne, 1959 \& Freedman 1975). This underscores the need to clarify the role of sutstitutes, so that they can become more than passive maintainers of the "baby sitting" philosophy scmetimes assocjated with their role. They can learn to perform a real function in facilitating learning and self-development of students.

Role senders (administrators and teachers) do have expectations of substitute teachers. These expectations must be articulated and communicated clearly and consistently in order to generate the type of response that will eliminate the uncertainties that seem to be associated with the role.

School district manuals across the country have stated two major functions concerning the role of substitute teachers:

(a) to carry out written lesson plans of the regular teacher,

(b) to perform routine "custodial" or disciplinary functions. (Education Research Service Circular \#4, 1962).

In most places, when a regular teacher is absent, arrangements are made through a central substitute teaching office to have a substitute teacher take her/his place. The substitute teacher is then expected to take the regular teacher's lesson plans and teach the 
students in such a manner that instructional continuity may occur.

A lesson plan can be defined as a clearly stated goal or objective with procedural and methodological steps showing how to achieve that goal. But because teaching styles vary, the personality of each teacher is unique, and a knowledge of students' learning style is acquired only after long-term association with them (Gregorc, 1979; Fischer \& Fischer, 1979; Dunn \& Dunn, 1979), effective teaching becomes difficult to achieve on a one or two-day assignment.

The substitute teacher can then be forced into a role of caretaker or that of a glorified baby-sitter; at best, he/she must dilute the lesson plans; thus, education goals for a day or two may remain unfulfilled.

Nevertheless, school districts nation-wide have adopted the "continuity policy" and have enunciated it in their substitute teacher's manual, a clear example of which is seen in the manual of the Covina Valley Unified School District, Covina, California (Education Research Service, \#4, 1962).

The objectives of the substitute program can be surmed up in one word: Continuity. Our goal is to eliminate the gaps in the education of the students which might result when a regular teacher is forced to be absent. Several important points are brought out by the use of the term "continuity" which can serve as a guide to us in determining what constitutes a desirable substitute program. The first of these is most obvious: There should not be a time when the students are left without a teacher. If the substitute is late, then there is a break in the continuity. If the students see a new substitute every day during the teacher's absence, there is again a loss of continuity. Continuity suffers if the standards of behavior established by the regular classroom teacher are not maintained by the substitute. It suffers again if the lesson plan is not followed, if the classroom and the class are not prepared by the substitute for the next day, if classroom procedures are drastically changed or altered, or if the hours kept by the regular teacher are not observed by the substitute. (p. 15). 
The Fomana Unified School District of California is succinct in its substitute teacher policy, "it is the obligation of substitutes to refrain from interferring with normal plans of the regular teacher" (Education Research Service, \#4, 1962, p. 21).

In Bedford, Indiana, the school does not expect the substitute to deviate from the regular program by introducing new major units of work unless approval is gained from the principal and/or supervisor. (Education Research Service, \#4, 1962, p. 22).

The expectation of the classroom teacher is also spelled out in the "Obligations and Responsibilities of the Regular Teacher, the Principal and the Substitute" of the Santa Barbara, California School District. The manual asks the question: "What does the classroom teacher hope the substitute will do?" The response is "Follow the regular plans and program of the day as closely as possible." (Education Research Service, \#4, 1962, p. 19). In Oregon, the school districts of Beaverton, Portland, Tigard, and Salem have clearly stated in their handbook for substitute teachers that it is the responsibility of the substitute teacher to carry out the lesson according to the teacher's plan and usual routine. But what is required of the substitute teacher may not be professionally feasible when all the circumstances of time constraints, misassignment and professional freedom are taken into account. The expected behavioral outcome must therefore be balanced against the range of freedom in role performance, as well as against the liklihood of achieving fixed goals.

In a study done by Schuler (1977), in which he combined 
organizational factors with interpersonal factors, he found that congruent patterns of organizational variables, specifically task design, organizational structure, and technology were associated with role conflict and ambiguity. It seems that the more incongruous the task requirement the more ambiguous the role is perceived. If the educational structure is so arranged that it cannot facilitate a balance between its fixed goals and what substitute teachers are reasonably expected to achieve, the result would be incongruity or substitute teachers role ambiguity.

\section{Task Characteristics}

The very nature of substitute teaching presents enormous problems for substitute teachers. Some of these problems are missassignment, student behavior, and lack of lesson plans. Misassignment is the term used by the Teachers Standard and Practices Commission to indicate that a teacher has been given an assignment to teach in a field for which (s)he has not been certified.

The practice occurs in the structure of the organization because substitutes must be obtained and dispatched quickly; and they are assigned based on their availability. Although efforts are made to eliminate misassignments, the practice still occurs.

Another task characteristic of substitutes is the behavior problem of students. "Hooty-toot-toot, here comes the substitute" is how Carr and Ryan (1974) have described the welcome a substitute is likely to receive in a classrocm. This speaks of student attitude to learning as well as the climate for learning in the classrocm. Freedman (1975) thinks that students sense a break in their instruction has occurred and take 
the opportunity to widen that breach. The substitute then has the twofold task of creating a favorable environment while trying to be faithful to the instructional goals as far as possible.

Lack of lesson plans is also associated with task characteristics. While the school district policy enunciates the following of the lesson plan as an important role for substitutes, many regular teachers do not provide adequate lesson plans (NEA Research Bulletin, 1955; Wotherspoon, 1977). Reasons are varied for not leaving an adequate lesson plan. They include concerns on the part of the regular teacher that the substitute may not be able to follow the plan which is either too complicated or the subject matter too difficult; some regular teachers who have been teaching for many years simplify their lesson plans to one line or sentence; and in many cases, the absence of the regular teacher is an emergency, so there is no time to develop an alternative plan.

That is why Heckman (1971) has recommended, among other things, that serious consideration be given to the development of administrative procedures which would facilitate instructional continuity in the absence of the regular classroom teacher. And recent literature has suggested some alternative procedures. (Manlove, 1979). Among these alternatives are:

(a) Employ on a daily basis and assign to a specific building a limited number of full-time substitutes with different teaching backgrounds, whether or not substitutes are needed.

(b) Make greater use of the library, resource centers and learning areas without the services of a substitute.

(c) Use the substitute purely as a specialist for enrichment of learning, with no attempt to follow sequential instructional goals. 
The benefits of having full-time substitutes are:

(1) Principals and other in-building administrators will have greater control of the recruiting, assigning, training, and evaluating of the substitutes.

(2). The substitutes will be familiar with the ruies of the school, enviroment, and some of the physical and social factors that will be useful to them in the classroom.

(3) The students will be more familiar with the substitutes. This could have the effect of reducing behavior problems. Using the library and resource centers can be cost effective, while at the same time allows the student to assume responsibility for his own education (Carr \& Ryan, 1974). Using the substitute as a specialist would enable the schools to draw from a wealth of talent in the community.

\section{INTERPERSONAI FACTORS}

Interpersonal factors include indices of the climate and structure which surround the focal role incumbent in an organization. Generally, the interpersonal factors which have been investigated include power of the role senders (often the supervisor), closeness of supervision, supportiveness of supervision, and functional dependence. These interpersonal factors are often used as moderators of the relationship between experienced role conflict and ambiguity and focal person's responses. For example, role conflict/ ambiguity may be correlated with performance, depending on how clearly job goals are defined or understood (Van Sell et al.,1981) or as Futrell and Parusuraman (1981) explains, clarity may affect job satisfaction by 
itself, or it may influence perceptions of role which in turn may influence satisfaction.

Although the interpersonal factors of the current study overlap at times with the organizational factors, they are discussed here as a separate issue under the general head of "administrative practices". Included in this section are such factors as importance of the sender, mode of interaction, feedback and participation. These factors are intertwined in the general discussion.

The supervisory efforts of school systems have been geared to the needs of their fulltime teaching staff while professional growth and morale building of the substitute teaching staff has been virtually neglected. Benthul (1963) believed that attitudes toward the substitute teacher must become more positive, in view of the substitutes' importance to any effective school program.

Elsbree and Reuter (1970) have pointed out that the administration of the substitute teaching service is made difficult by the impossibility of predicting needs from day to day on the various levels of the school system and in individual buildings. They pointed out further that the substitute teaching services need improvements on two major fronts: (1) Providing better overall working conditions for the substitute. (2) Providing better professional articulation between the substitute teachers and the education program of the school. They are concerned that substitute teachers be given the same professional consideration as regular teachers in terms of staff development procedures.

The discussion which follows addresses the needs of regular teachers, but by implication applies to substitute teachers as well. 
Administrative Practices

The function of the administrative team is, among other things, to motivate teachers and workers. The literature on school management has not only indicated the need for the administrative team to motivate teachers, but has also recommended the type of motivation that would be effective. These include "intrinsic rewards" such as comunity support; positive social interactions, and agreement with district's goals (U. of 0. 1980: Dawson, 1981); a decentralized authority structure composed of independent teaching teams; positive feed back and recognition (U. of 0. 1981). Dawson (1981) also pointed out that teacher motivation was influenced by the "compatibility between project and goals". Thus, motivation was enforced when teachers participated in basic skills projects but was lessened by involvement in career education projects. Erlandson and Pastor (1981) reported a study of 150 high school teachers in ten high schools, which suggests that the changes in organizational structure necessary to stimulate teachers to excellence can be wrought by the building principal. The study measured "the presence and fulfillment of higher order need strengths" in the teachers studied. Higher order need strengths were defined as desires for involvement in decision making, challenge on the job, expression of creativity, freedom and independence, and the opportunity to use a variety of skills.

Bruno (1981), stated that there is a relationship between high quality teachers and certain type of non-monetary benefits such as computer based instructional programs and what he calls "institutional profit sharing", a type of pride of "ownership" in the school. 
A similar emphasis is made by Rogus \& Matczynski (1977) when they stated that "higher needs" are satisfied by shared decision making and involvement in the development of the organization. In other words, satisfaction of these higher needs is shown to relate significantly to improved employee performance.

The literature seems to be building a case for several factors affecting the substitute teaching services:

(a) Substitute teachers need "intrinsic rewards" to motivate them.

(b) Substitutes activities in the classroom ought to be compatible with their goals.

(c) Administrative supervision is essential to substitutes" performance; and

(d) Substitutes need participation and feedback to perform effectively.

Futrell \& Parasuraman (1981) have found that there is a relationship between perceptions of role and work satisfaction. Although role conflict has a negative influence on company satisfaction and role ambiguity had a negative influence on work satisfaction, the authors suggest that any indication of dissatisfaction resulting from confusion about role expectation must have administrative implications in the sense that the problem must be identified and corrected.

SUMMARY: ROLE CONFLICT AND ROLE AMBIGUITY

The literature gives strong. support for vlewing role perceptions (in the form of role conflict and role ambiguity) as antecedents to behavioral outcomes, such as satisfaction or performance (Keller, 
Szilayi, 1978; Miles, 1975 \& Schuler, 1977).

Ever since Kahn, Wolfe, Quinn, Snoek and Rosenthal (1964)

reported that role conflict and role ambiguity were associated with job related tension and dissatisfaction, and unfavorable interpersonal outcomes, such as lower levels of trust, liking, and respect for role senders, many researchers have replicated their findings. Rizzo, House and Lirtzman, (1970) found a direct relationship between experienced role conflict and job dissatisfaction, anxiety and tension and propensity to leave the organization. Tosi (1971) found role confict to be directly felated to anxiety and job threat and inversely related to job satisfaction.

Similar relationships between role ambiguity and personal outcomes were reported. Kahn et al.,(1964) found that experienced role ambiguity was directly related to job tension, dissatisfaction and futility, and adversely related to self-confidence. Similar findings were reported by Hamner \& Tosi (1974) Lyons, (1971) Ivancevich and Donnelly (1974), as well as by Locke (1968), whom Miles (1975) reported to have concluded that persons were more satisfied and effective under specific performance goal conditions than under more ambiguous task instructions to "do your best" (p. 335).

The substitute teaching system, with its many organizational and interpersonal factors suggests a muddle through approach to the task. The present research poses certain questions in the following chapter to more clearly address the question of what makes the su stitute teacher more effective in the classroom, and to what extent is role ambiguity/conflict related to that effectiveness. 
CHAPTER III

RESEARCH METHODOLOGY

A variety of strategies was used to answer the research questions pertaining to role conflict, role ambiguity and effectiveness. The purpose was primarily exploratory, and the method descriptive. The procedures used in selecting the sample and in collecting the data reflected the exploratory approach to obtaining information for the study. Although the research design included some elements of the design used by Rizzo, House and Iirtzmen (1970), it was developed with the peculiar needs of substitute teachers in mind. This chapter presents more detailed information on the methods used in this research, including participants, instrument design, and procedure for collecting data.

Specific questions answered were the following:

(1) To what extent, if any, is there an inter-sender role conflict? Do regular teachers and administrators have a common view regarding the role of the substitute teacher?

(2) According to administrators, regular teachers and substitute teachers, is there role ambiguity regarding the work of substitute teachers?

(3) According to administrators, regular teachers and substitute teachers, how effective are substitute teachers at specified tasks?

(4) What is the relationship between the perceptions of educators regarding administrative practices within the substitute teaching services and what is actually done? 
(5) What is the relationship between administrative practices and effectiveness?

Hypotheses to be tested were:

(1) The role expectations held of substitute teachers by regular teachers and administrators are different from those held by the substitute teachers themselves.

(2) The more ambiguous substitute teachers perceive their role, the less effective they will consider themselves in the classroom.

(3) The performance of substitute teachers in non-Chapter 1 schools is more positively perceived by all groups of educators than that of substitute teachers in Chapter 1 schools.

Stated in the conventional null, the statistical hypotheses to be tested were:

(1) There is no difference between expectations held of substitute teachers by administrators and regular teachers and those held by the substitutes themselves.

$$
\begin{array}{rlrl}
\mathrm{H}_{0}: \overline{\mathrm{x}}_{1} & =\overline{\mathrm{x}}_{2}=\overline{\mathrm{x}}_{3} & \overline{\mathrm{x}}_{1} & =\text { mean for administration } \\
\mathcal{X}=.05 & \overline{\mathrm{x}}_{2} & =\text { mean for teachers } \\
\overline{\mathrm{x}}_{3} & =\text { mean for substitutes }
\end{array}
$$

(2) There is no relationship between role ambiguity and effectiveness in the classroom as perceived by substitute teachers.

$$
\begin{aligned}
\mathrm{H}_{0}: \bar{x}_{1} & \neq \bar{x}_{2} & \bar{x}_{1}=\text { mean for role ambiguity } \\
\propto & =.05 & \bar{x}_{2}=\text { mean for effectiveness }
\end{aligned}
$$

(3) There is no difference between the perceived performance of substitute teachers in non-Chapter scinools and that of the Chapter schools.

$$
\begin{aligned}
H_{0}: \bar{x}_{1}=\bar{x}_{2} & \bar{x}_{1}=\begin{array}{l}
\text { mean for non-Chapter } \\
\text { schools }
\end{array} \\
\alpha=.05 & \dot{\bar{x}}_{2}=\begin{array}{l}
\text { mean for Chapter } \\
\text { schools }
\end{array}
\end{aligned}
$$




\section{Participants}

The participants in this study were regular teachers, substitute teachers and administrators from the Educational Consolidation and Improvement Act (ECIA, 1981) Chapter 1, and non-Chapter 1 high schools in the Portland Public schools. It was thought important to include this socio-economic variable to determine what impact, if any, the location of school had on the perceptions of the participants. A questionnaire was developed and administered to sixty regular teachers, sixty substitute teachers and sixty administrators. Ten regular teachers were randomly selected from the staff roster from each of the six chosen schools. The substitute teachers were randomly selected from a roster of names supplied by the Portland School District. The roster consisted of 72 substitute teachers and addresses grouped according to schools in which they served most frequently. A substitute teacher was placed on the roster in the appropriate group if (s)he had served at least twice in any of the six selected schools within the 1981-82 school year. If a substitute teacher served in both Chapter 1 and non-Chapter 1 schools, (s)he was placed in the group in which (s)he served more. The completed list of substitute teachers had twelve names and addresses in each of the six groups representing the six schools included in the study.

The administrators were randomiy selected from the participating schools. Administrators included principals, vice-principals and department heads. This was done to get a large enough sample of educators who might have a perspective other than that of a regular classroom teacher. 
Instrument

The questionnaire developed consisted of 35 questions. Each question was divided into two items: A - Ideal, and B - Actual.

e.g. Should the substitute observe and evaluate student behavior for the regular teacher? - (Ideal)

Does the substitute abserve and evaiuate student behavior for the regular teacher? - (Actual)

A seven-point likert-type scale was used to measure the subjects' responses.

eg. \begin{tabular}{lllllll}
1 & 2 & 3 & 4 & 5 & 6 & 7 \\
\hline IOW & & & & & & High
\end{tabular} (See Appendix D)

By using a two-item question (Ideal \& Actual) one could determine the degree to which ambiguity was present. Ambiguity was determined by the difference between the "Ideal" and the "Actual". Item $A-B=A m b i g u i t y$, or the extent to which the role is underdefined. The "Ideal" and the "Actual" could also measure the degree to which congruency was present in the other perceptions of the respondents.

A scale of 12 items were used to measure role conflict between role senders,i.e, between administrators and regular teachers. The same items were also used to measure role conflict between focal person and role senders,i.e, between substitutes and both regular teachers and administrators.

To measure effectiveness, a scale of 9 items was developed. Effectiveness was also determined by the difference betiween the "Ideal" and the "Actual",i.e, B - A. To measure the influence of the socio-economic status of the workplace, an 8-item scale was used. Administrative practices were also measured using 22 items. 
The following items were used from the questionnaire to make tables and scales.

\section{Tables}

Role Conflict

Role Ambiguity

Effectiveness

Socio-Economic Influence

Administrative Practices
Items

$$
\begin{aligned}
& 2 A, 3 A, 4 A, 5 A, 6 A, 7 A, 8 A \\
& 9 A, 10 A, 11 A, 12 A, 18 A . \\
& 1 A, 1 B . \\
& 19 B, 4 B, 6 A B, 7 A B, 8 A B, \\
& 9 A B, 10 A B, 11 A B, 18 A B . \\
& 19 B, 4 B, 6 A B, 7 A B, 8 A B, \\
& 9 A B, 10 A B, 11 A B, 18 A B . \\
& 5 A B, 13 A B, 14 A B, 15 A B, 16 A B, \\
& 17 A B, 20 A B, \text { through } 35 A B .
\end{aligned}
$$

\section{Procedure}

A pilot test of the instrument was conducted to determine clarity of questions and coherence of design. The questionnaire was distributed to 70 members of the Franklin High School staff at one of its regular staff meetings. No substantial change was made to the instrument at that time, although the pilot did indicate that the respondents did have difficulty responding to a few of the administrative policy questions. The questionnaire was therefore administered to participants associated with six high schools in the Portland Public Schools.

Currently, there are only three Chapter 1 high schools in the Portland School District. All three were used in this study. Of the eight remaining high schools, three were chosen with characteristics similar to each other, such as size of enrollment, and from a location generally regarded as middle class or above. These were designated as non-Chapter 1 schools. 
The questionnaire was placed in the teachers' and administrators' boxes with a cover letter explaining the significance of the study and with instructions to leave the completed questionnaire in a sealed envelope, which was provided, with the head secretary.

The substitute teachers received the questionnaire through the mail with a self-addressed envelope enclosed.

Two weeks after the questionnaires were distributed, postcards were sent to all those who had not returned the instruments. of the 180 questionnaires distributed, a total of $82 \%$ were returned. Teachers returned $88 \%$, administrators returned $88 \%$, and substitute teachers returned 71\%. With reference to mail questionnaires, Kerlinger (1964) says, "Higher percentages are rare. At best, the researcher must content himself with returns as low as 50 or 60 percent" (p.414).

Table I illustrates the number and percent of questionnaires that were distributed and returned in this study. 
TABLE I

NUMBER AND PERCENT OF QUESTIONNAIRES DISTRTBUTED AND RETURNED

\begin{tabular}{|l|c|c|c|}
\hline Respondent Group & No. Sent & No. Returned & Percent \\
\hline Adnintstratars & 60 & 53 & 88 \\
Regular Teachers & 60 & 53 & 88 \\
Substitute Teachers & 60 & 43 & 71 \\
\hline Total & 180 & 149 & 82 \\
\hline
\end{tabular}


Reliability

Each item of the questionnaire was rated on a seven-point scale, the mid-point of which indicated a neutral response, and the end points a positive and negative perception respectively. After the data were collected, an effectiveness scale was developed. Reliability tests were performed to determine the intermal consistency of the instrument. The reliability coefficient alpha for the effectiveness scale was .82 .

High reliablilites contribute to a higher level of confidence in the conclusions one draws from the data. Although the removal of certain items could increase the alpha reliability of the scales in this study, removal of such items could decrease the overall validity by eliminating items essential to the meaning of the subject. Kerlinger does not specifically state an acceptable reliability coefficient; however, he has implied, and the general concensus is, that a reliability of .6 is an acceptable level; therefore the reliability coefficient meets the criterion. 


\section{CHAPTER IV}

\section{RESULTS}

Five questions and three hypotheses were stated regarding the role expectations of select educators pertaining to the substitute teaching services. These hypotheses are statements about perceived role conflicts, role ambiguity, and a statement about the impact of the socio-economic status of the workplace on the perceptions of educators. In this chapter the results of tests of these hypotheses are presented and discussed. Also, in keeping with the exploratory nature of the research, the results of other procedures used to answer specific questions relative to ambiguity and effectiveness are described and discussed.

\section{Role Conflict}

Hypothesis 1. The role expectations held of substitute teachers by regular teachers and administrators are different fram those held by the substitute teachers themselves.

Underlying this hypothesis is the assumption that different role senders have a direct influence on the way substitute teachers perceive their role, and therefore contributes to role conflict. This assumption is based on empirical data, and the role episode model which suggests that when role senders give the focal person conflicting cues, the focal person tends to be less effective. To test the hypothesis, ANOVA was performed on each variable 
across the three groups of educators to determine an overall $F$ ratio on individual variables (see Table II). Results show that there was no significant difference among the means of these three groups of educators. This suggests that there is no conflict between administrators, regular teachers, and substitute teachers about the role of substitute teachers. AIl three groups of educators have a common view of what to expect of substitute teachers in the classroom. The null hypothesis cannot be rejected. Focal person and role-senders are in harmony with respect to role expectations.

For further clarification on role conflict a research question was asked:

Research Question: To what extent, if any, is there an intersender role conflict? Do regular teachers and administrators have a common view regarding the role of the substitute teacher?

The major assumption underlying this research question is that an effective participant in the educational process has a definite understanding of and an appreciation for his/her role or function and that of other personnel as they relate to the goals of the institution. This research question is also related to Hypothesis $I$, focal person vs role-senders conflict. The data in Table II show there is no conflict between the groups. Figure 2 was therefore created to show the extent of agreement by the total group with respect to the 11 statements defining the role of substitute teachers. Figure 2 shows that the majority of the role descriptors were supported by the respondents. Eight of these role descriptors ranged from "slightly agree" to "strongly agree". 
TABLE II

FOCAL PERSON VS ROIE-SENDERS CONFITCT AS REPORTED

BY ADMINISTRATORS, REGULAR TEACHERS AND SUBSTITUTE TEACHERS

\begin{tabular}{|c|c|c|c|c|c|}
\hline \multirow{2}{*}{ VARIABIES } & \multicolumn{3}{|l|}{ Mears : } & \multirow{2}{*}{$\begin{array}{l}\text { Overall F } \\
\text { Pram ANOVA } \\
\text { df }=2, \quad 142-146 \\
\end{array}$} & \multirow[b]{2}{*}{$\begin{array}{l}\text { Significant } \\
\text { Paliwive } \\
\text { Differences a }\end{array}$} \\
\hline & Aministrators & $\begin{array}{l}\text { Regular } \\
\text { Teachera (2) }\end{array}$ & $\begin{array}{l}\text { Substitute } \\
\text { Teachers ( } 3 \text { ) }\end{array}$ & & \\
\hline $\begin{array}{l}\text { Substitutes' role should be } \\
\text { Custodial }\end{array}$ & ${ }_{(n=53)}^{1.98} 1.4$ & $\underset{(n=52)}{2.29} 1.65$ & $\begin{array}{l}2.141 .52 \\
(n=42)\end{array}$ & .53 & \\
\hline $\begin{array}{l}\text { Substitutes role should be } \\
\text { guest teacher }\end{array}$ & $\underset{(n=53)}{2.85} 1.91$ & ${ }_{(n=52)}^{3.04} 2.10$ & ${ }_{(n=42)}^{3.26} 2.26$ & .46 & \\
\hline $\begin{array}{l}\text { Substitutes role should be } \\
\text { observer and evaluator of } \\
\text { students' behaviar }\end{array}$ & $\underset{(n=53)}{4.83} 1.70$ & $\left.{ }_{(n=53)}^{5.13}\right)^{2.06}$ & ${ }_{(n=43)^{2.01}}^{2.01}$ & .35 & \\
\hline $\begin{array}{l}\text { Should malntain regular teacher's } \\
\text { standard of behavior }\end{array}$ & $\underset{(n=53)^{6.28}}{1.36}$ & $\underset{(n=53)^{6.53}}{6.72}$ & $\underset{(n=42)}{6.31} .92$ & .85 & \\
\hline $\begin{array}{l}\text { Should prepare class and class- } \\
\text { room for next day's wark }\end{array}$ & ${ }_{(n=53)}^{5.40} 1.55$ & ${ }_{(n=51)}^{4.51} 1.92$ & $\underbrace{4.56}_{(n=43)} 2.31$ & $3.42^{\circ}$ & none \\
\hline Should carrect students' wark & $\underset{(n=53)}{3.92} 2.04$ & $\begin{array}{l}4.33 \\
(n=51)\end{array}$ & $\underset{(n=42)}{4.14} 1.91$ & .53 & \\
\hline Should keep acourate records & ${ }_{(n=53)}^{6.77}$ & $\underset{(n=53)}{6.55} 1.20$ & $\underset{(n=43)^{62}}{6.58}$ & .89 & \\
\hline $\begin{array}{l}\text { Should use non-teaching time to } \\
\text { help individual students }\end{array}$ & $\underset{(n=53)}{5.47} 1.65$ & $\begin{array}{l}4.921 .81 \\
(n=52)\end{array}$ & $\underset{(n=42)}{4.71} 2.04$ & 2.25 & \\
\hline $\begin{array}{l}\text { Should carry out regular } \\
\text { teacher's lesson plan }\end{array}$ & $\underset{(n=52)}{6.56}$ & $\underset{(n=53)}{6.58} .60$ & $\ln _{(n=42)}^{6.36} .91$ & .99 & \\
\hline $\begin{array}{l}\text { Should prevent instructional } \\
\text { loss }\end{array}$ & $\underset{(n=52)}{6.50} .83$ & $\underset{(n=53)}{6.46} \cdot .72$ & $\begin{array}{l}6.421 .10 \\
(n=43)\end{array}$ & .10 & \\
\hline $\begin{array}{l}\text { Substitutes' role should prevent } \\
\text { instructional loss }\end{array}$ & $\begin{array}{c}5.38 \\
(n=52)\end{array}$ & $\left.\ln _{(n=53)}^{5.26}\right)^{1.62}$ & $\begin{array}{l}4.05 \\
(n=43)^{1.98}\end{array}$ & 8.940 .0 & $3<2,1$ \\
\hline
\end{tabular}

Following a significant overall $F$, significant palrwise differences were determined by using the student Neunan - Keuls. Procedure to examine differences between all possible palrs of maans, $p_{5} .05$ $\bullet p \leq .05$ ... p $=.001$ 


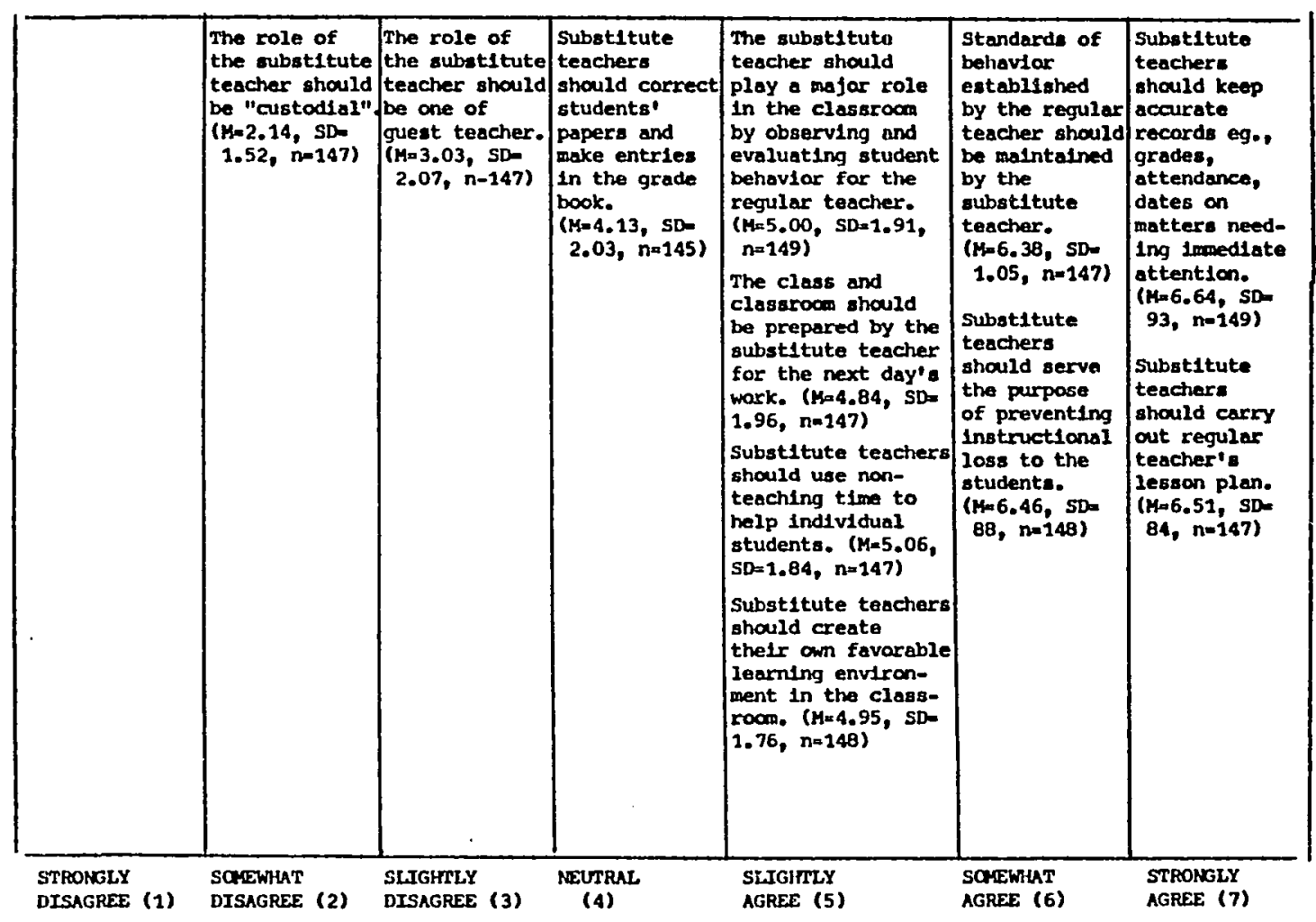

Figure 2. Extent of agreenent with 11 statenents defining role of substitute teachers. Sample 1s the total sample of adninistrators, regular teachers, and substitute teachers (n=149). In parenthesis
following each statement 1s that statement is mean, standard deviation and sample aize. 
One item fell in the neutral column, and two fell below the neutral point. With respect to the two items that fell in the "disagree" colurns, it is quite possible that the respondents were not quite clear as to what was meant by "custodial" or what was meant by "guest teacher", two concepts that were included in those two questions.

The latter, however, was fully defined as part of the question in the questionnaire. It could be that all groups of educators were making it clear that they want to continue using the regular teacher's lesson plan which is one of the camponents of the instructional continuity principle, as a basic task. They did not want too much radical change from existing practices within the substitute teaching services.

In sumary, there is no role conflict between the three groups of educators - between the focal person and the role senders. This is consistent with previous studies in role theory and organization theory (Rizzo et al.,1970). In addition, there is high agreement on the role descriptors on the statements defining the role of substitute teachers. Perhaps further insight into the substitute teachers' experience might be gained by looking into the other aspect of role theory, - ambiguity.

\section{Role Ambiguity}

Research Question: According to administrators, regular teachers and substitute teachers, is there role ambiguity regarding the work of substitute teachers? 
In keeping with previous research, role ambiguity was measured by looking at the focal person's perception of his role. In this case, the substitutes' scores on two variables were examined to determine (a) how clearly they perceived their roles should be defined, and (b) to what extent they thought it was defined. The means for those two variables are 5.9 and 4.8 respectively. The means for ambiguity or under-defined role is 1.21. This represents a lack of role clarity that was present in the mirid of substitute teachers (see Table III).

ANOVA was also performed using three variables:

(1) roles should be defined, (2) role is defined, and (3) role is underdefined, as reported by three role types: administrators, regular teachers and substitute teachers. The overall F fran ANOVA (4.035) shows that there was significant difference among the perceptions of the three groups of ecucators regarding how clearly role should be defined. Administrators show a mean of 6.5, regular teachers 6.3 and substitute teachers 5.9. The student Nersnan-KeuIs procedure was used to examine the differences between all possible pairs of means. It was found that there were signifIcant differences between the means of substitute teachers and administrators ( $p \leq .05)$. This suggests that substitute teachers prefer less role definition than administrators, and desire greater freedom to teach and exercise judgement in the classroom. This is consistent with Porter et al (1979) who concluded that classroom teachers see their role as decision makers in the classroom. 
There were no significant differences in role definition. Regarding whether role is under-defined, ANOVA shows a signigicant F (5.698) at .01. The student Neuman-Keuls procedure shows that substitute teachers believe that their role is much more ambiguous than do administrators and regular teachers. 
SUBSTITUTE TEACHERS'ROLE DEFINTTION - AMBIGUITY AS REPORTED BY THREE ROLE TYPES: ADMTNISTRATORS, REGULAR TEACHERS, SUBSTITUTE TEACHERS.

\begin{tabular}{|c|c|c|c|c|c|}
\hline \multirow{2}{*}{ VARIABLES } & $\begin{array}{l}\text { Administrator: } \\
\text { (1) }\end{array}$ & $\begin{array}{l}\text { Regular } \\
\text { Teachers } \\
\text { (2) }\end{array}$ & $\begin{array}{l}\text { Substitute } \\
\text { Teachers } \\
\text { (3) }\end{array}$ & \multirow{2}{*}{$\begin{array}{l}\text { Overall } \mathrm{F} \\
\text { from ANOVA } \\
\mathrm{df}=2, \quad 144-146\end{array}$} & \multirow{2}{*}{$\begin{array}{l}\text { Significant } \\
\text { Paiwise Mean } \\
\text { Differences }\end{array}$} \\
\hline & SD & $S D$ & $S D$ & & \\
\hline Role should be defined(QIAR $)^{1}$ & $\begin{array}{l}6.5 \\
(n=53)\end{array}$ & $\begin{array}{l}6.3 \quad 1.15 \\
(n=52)\end{array}$ & $\begin{array}{l}5.9 \quad 1.42 \\
(n=42)\end{array}$ & $4.035 *$ & $3<1$ \\
\hline Role is defined (QIBR) ${ }^{2}$ & $\begin{array}{l}4.4 \quad 1.5 \\
(n=53)\end{array}$ & $\begin{array}{l}4.3 \quad 1.6 \\
(n=53)\end{array}$ & $\begin{array}{l}4.8 \quad 1.7 \\
(n=43)\end{array}$ & 1.175 & \\
\hline $\begin{array}{l}\text { Role is underdefined (QIAR } \\
\text { minus QIRB) with negative } \\
\text { numbers collapsed to zero. }\end{array}$ & $\begin{array}{l}2.17 \quad 1.47 \\
(n=53)\end{array}$ & $\begin{array}{l}2.11 \quad 1.5 \\
(n=52)\end{array}$ & $\begin{array}{l}1.21 \quad 1.57 \\
(n=42)\end{array}$ & $5.698 * *$ & $3 \leftarrow 2,1$ \\
\hline
\end{tabular}

a Following a signiflcant overall F, significant pairwise mean differences were determined using the student - Neuman - Keuls . Procedure to examine differences between all possible pairs of means (p $\leq$.05).

$* p \leq .05 \quad * p \leq .01$

1. Zuestion 1A recoded

2. Question $1 \mathrm{~B}$ recoded 


\section{Effectiveness}

Research Question: According to administrators, regular teachers, and substitute teachers, how effective are substitute teachers at specified tasks?

To answer this question, it was important to develop a measure of effectiveness. This was done by calculating the difference between the Ideal and the Actual or B - A. The difference was operationally defined as effectiveness. Table IV, however, shows three different effectiveness scores: (1) Substitute teachers are effective educators. This was a direct question that got at the effectiveness issue in an all-encompassing manner. The three groups of educators or role types differed in their perception of the substitute teachers effectiveness. More specifically administrators and regular teachers saw substitute teachers less effective than substitutes saw themselves. $\quad(M=4.63$; 4.78; 5.28; the overall F from ANOVA (3.47) is signigicant at the .05 level. (2) Eight other individual variables were calculated using ANOVA; (3) the average score of the eight variables were also calculated. Except for two variables, "substitutes observe and evaluate student's behavior", and "substitutes maintain standards of behavior set by regular teachers", all other mean differences were significant at the .01 and .001 Ievels. There appears to be agreement between the groups on the level of effectiveness demonstrated by substitute teachers in the area of responsibilities for behavior control. In total, the results seem to suggest that substitute teachers are perceived by administrators and regular teachers as ineffective in performing these 8 tasks. 
SUBSTITUTE TEACHERS' EFFECTIVENESE AS REPORTED BY THFEE ROLE TYPES: ADHINISTRATORS, REGURAR TEACHERS,

Means and Standard Deviations

\begin{tabular}{|c|c|c|c|c|c|c|}
\hline \multirow[b]{2}{*}{ VARIABLES } & \multirow{2}{*}{$\begin{array}{l}\text { Adrinfstrators } \\
\text { (1) } \\
\text { M SD } \\
\end{array}$} & \multirow{2}{*}{\multicolumn{2}{|c|}{$\begin{array}{l}\begin{array}{l}\text { Regular } \\
\text { Teachers (2) }\end{array} \\
\text { M SD } \\
\end{array}$}} & $\begin{array}{l}\text { Substitute } \\
\text { Teachers ( } 3)\end{array}$ & \multirow{2}{*}{$\begin{array}{l}\text { Ovorall } F \\
\text { from ANOWA } \\
\text { dfan? 144 } \\
\end{array}$} & \multirow{2}{*}{$\begin{array}{l}\text { Significant } \\
\text { Palrwlse } \\
\text { Hean Differences }\end{array}$} \\
\hline & & & & $\underline{S D}$ & & \\
\hline $\begin{array}{l}\text { Substitute teachers are } \\
\text { effective educators }\end{array}$ & ${ }_{(n=52)}^{4.63} 1.24$ & \multicolumn{2}{|c|}{$\underset{(n=52)}{4.78} 1.08$} & ${ }_{(n-43)}^{5.28} 1.40$ & $3.47^{\circ}$ & $1,2<3$ \\
\hline $\begin{array}{l}\text { Substitutes abserve and } \\
\text { evaluate students' behavior }\end{array}$ & ${ }_{(n=53)}^{-1.001 .40}$ & \multicolumn{2}{|c|}{${ }_{(n=53)}^{-0.98} 1.10$} & $-0.74{ }_{(n=42)}^{1.25}$ & .61 & N.S. \\
\hline $\begin{array}{l}\text { Substitutes maintaln regular } \\
\text { teachers standards of behavior }\end{array}$ & $\begin{array}{c}-1.921 .48 \\
(n=53)\end{array}$ & \multicolumn{2}{|c|}{${ }_{(n=53)}^{-1.77} 1.41$} & ${ }_{(n=41)}^{-1.39}{ }^{1.32}$ & 1.71 & N.S. \\
\hline Prepare class for next day & ${ }_{(n=53)}^{-1.68}{ }^{1.60}$ & $\underset{(n=50}{-1.08}$ & $0)^{1.41}$ & ${ }_{(n=42)}^{-0.62} 1.01$ & $6.99 \cdot 0$ & $1<2,3$ \\
\hline Correct students' work & ${ }_{(n=50)}^{-1.18} 1.48$ & $\stackrel{-1.57}{(n=51}$ & 11.59 & $-0.36{ }_{(n=42)} \cdot 79$ & $9.34 \cdots$ & $1,2<3$ \\
\hline Keep accurate records & ${ }_{(n=53)}^{-1.87}$ & $\stackrel{-1.77}{i n=53}$ & 3) ${ }^{1.53}$ & $-i_{(n=42)}^{1.01}$ & $7.70 \cdots$ & $1,2<3$ \\
\hline $\begin{array}{l}\text { Use non-teaching time to help } \\
\text { Individual students }\end{array}$ & ${ }_{(n+52)}^{-2.36}{ }^{1.96}$ & $\underset{(n=52}{-2.12}$ & 2) $)^{1.69}$ & ${ }_{(n=41)}^{-1.00} 1.30$ & 8.13000 & $1,2<3$ \\
\hline $\begin{array}{l}\text { Follow regular teachors' } \\
\text { lesson plans }\end{array}$ & ${ }_{(n=52)}^{-1.57}$ & \multicolumn{2}{|c|}{${ }_{(n=52)}^{-1.55} 1.41$} & $-i_{(n=43}^{31}$ & $16.95 \cdot 1 \bullet$ & $1,2<3$ \\
\hline $\begin{array}{l}\text { Greate favorable learning } \\
\text { enviroment }\end{array}$ & -1.001 .19 & \multirow{2}{*}{\multicolumn{2}{|c|}{$\begin{array}{l}-.921 .21 \\
-1.54=51)^{1.21} \\
-1.83\end{array}$}} & $-\underbrace{.14}_{(n=43)} .41$ & $9.65 \cdot 00$ & $1,2<3$ \\
\hline Average Perceived Effectiveness & $-1.63 \quad .94$ & & & $-.73 \quad .64$ & $16.20 \bullet \bullet$ & $1,2<3$ \\
\hline
\end{tabular}

Following a significant overall $F$, significant pairwise differences were deternined using the student Neuran - Kouls Procedure to examine differences between all possible pairs of means (ps.05).

- p $\leq .05 \quad \cdots p \leq .01 \quad \cdots p \leq .001$ 
Ambiguity and Effectiveness

Hypothesis 2. The more ambiguous substitute teachers perceive their role, the less effective they will consider themselves in the classroom.

The major assumption underlying this hypothesis is the assumption that role ambiguity has a negative effect on the way substitute teachers perceive their ability to perform in the classroom. Role ambiguity was defined as the degree to which clear information is lacking regarding the expectations associated with a role, regarding methods of fulfilling known role expectations, and regarding the consequences of role performance.

As Table $\mathrm{V}$ shows, there is a negative correlation between ambiguity and effectiveness. Three variables are significant at the .05 level. These are: (1) Substitutes maintain regular teachers' standards of behavior; (2) substitutes prepare class for the next day, and (3) Substitutes keep accurate record. The implications of this finding are important to the continuity principle, but most important, is that effectiveness of substitute teachers will only improve as the ambiguity surrounding these tasks is removed. 
TABLE V

CORRELATIONS OF SUBSTITUTE TEACHERS'

ROLE AMBIGUITY WITH THEIR EFFECTIVENESS:

SUBSTITUTE TEACHERS' PERSPECTIVE

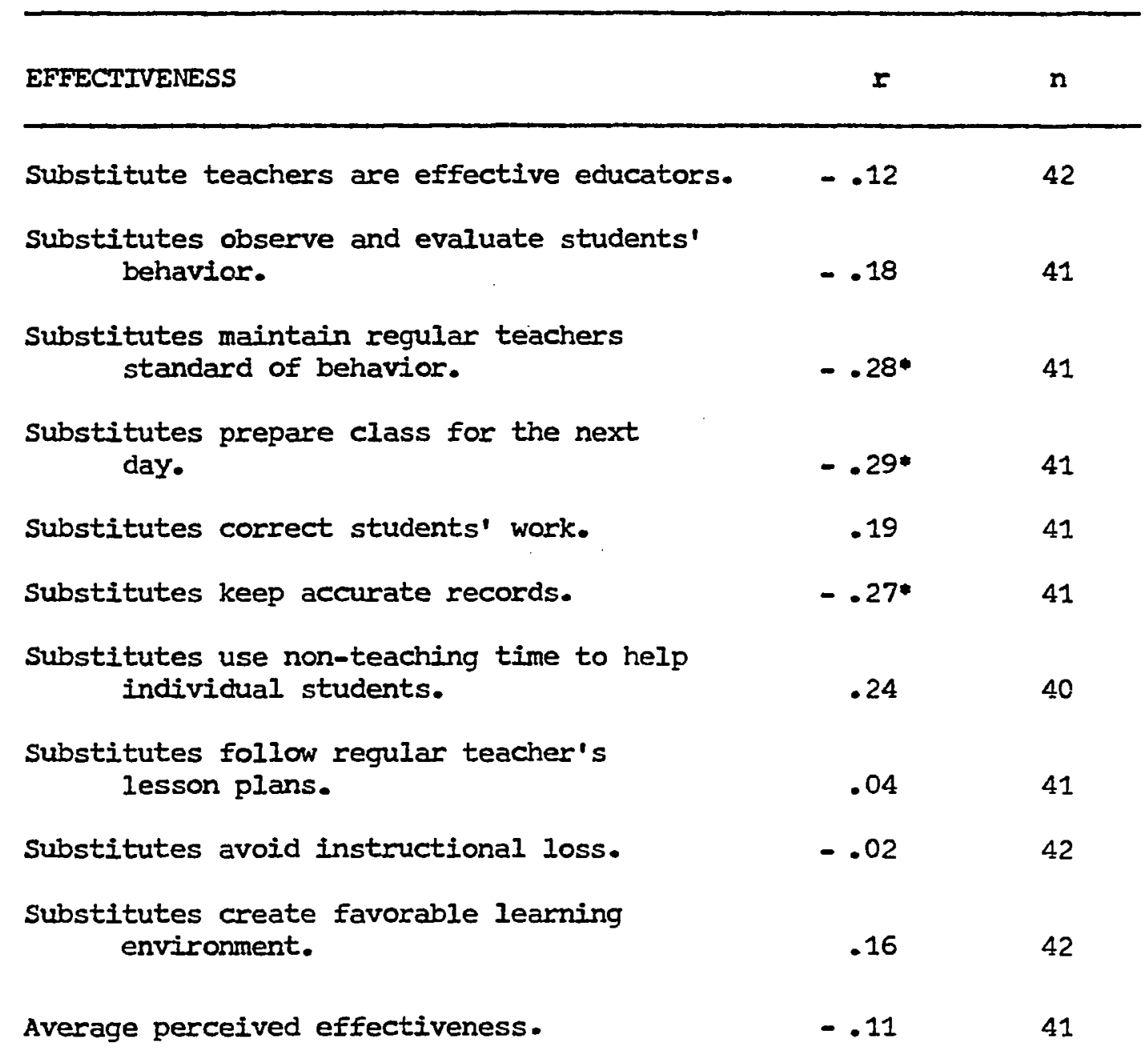

$* p \leq .05$ one tailed tests of statistical significance 
Most of the correlations show a negative relationship between effectiveness and ambiguity. Although the level of correlation of many individual variables is low, there are others that are significant. For example, the correlation between subsitutes' performance in maintaining standards of behavior set by the regular teacher and ambiguity was significant at the .05 level $(r=-.28)$. The relationship between ambiguity and substitute teachers preparing the class for the next day was also significant. So too, was "keeping accurate records" and ambiguity; these were also significant at .05. Having three significant results in 11 correlations $@ \alpha=.05$ is 5.45 times chance expectation.

It is important to note that although there were four positive correlations, none of them was significant. "Substitutes correct student work" had a correlation of .19; "Substitutes create favorable learning environment" had a correlation of .24; and "Substitutes follow regular teacher's lesson plans" had a correlation of .04. The The low correlation of the latter variable pertaining to lesson plans suggests that the providing of instructional continuity is not done with any great deal of enthusiasm.

These data lend significant support to the hypothesized relationship between ambiguity and effectiveness. Effectiveness then appears to be a function of role clarity. Thus, the hypothesis is supported. 


\section{Socio-economic Influence}

Hypothesis 3. The performance of substitute teachers in non-Chapter 1 schools is more positively perceived by all groups of educators then that of substitute teachers in Chapter 1 schools.

The underlying assumption of this hypothesis is that schools that are located in the low socio-economic areas demand greater effort on the part of all personnel, whether they be administrators, regular teachers or substitute teachers. It was expected that because of the greater effort required, personnel in the low socio-economic areas would perceive the work of substitutes in a negative way, that is not achieving the high standard set by the federally funded program called Chapter 1. Not only are high standards of instruction expected, but also dedicated effort to keep records and to do many other reporting procedures.

The data show, however, that there is no significant difference between the means of Chapter 1 and non-Chapter 1 scores on most of the eleven variables tested, across the three groups of educators (Table VI).

The exceptions are:

(1) Administrators in Chapter 1 schools are much more positive about the work of substitute teachers than are administrators in the higher socio-economic or non-Chapter 1 areas regarding the carrying out of teachers lesson plans $(\mathrm{M}=-1.22,-1.86) \mathrm{p} \leq .031$.

(2) Regular teachers from the same two socio-economic groups have different perceptions about the effectiveness of substitute teachers. The teachers from the higher socio-economic areas perceive substitutes 
as less effective overall than did the teachers from the low socio-economic areas. This was confirmed using both types of measures (BMA; or item $B$ above) $\mathrm{p} \leq .014$ and .046 respectively. Regarding substitutes' effectiveness in maintaining standards of behavior set by the regular teacher, the teachers from the lower socio-economic areas are again much more positive about the substitutes effectiveness in performing that task than are the teachers from the higher socio-economic areas. ( $p \leq .007)$.

(3) The substitute teachers themselves differ on two effectiveness variables. In both cases the higher economic area respondents are more positive about the substitutes effectiveness than are the respondents from the lower economic area. The variables are (a) use of non-teaching time and (b) overall score effectiveness. ( $\mathrm{p} \leq .0005$; and .0385). Although these exceptions snow some group differences the prevailing response is that the effectiveness of substitute teachers, or lack of it, is more alike than different.

In summary, the hypothesis that states that substitute teachers in non-Chapter 1 or higher socio-economic areas are more positively perceived than those in lower socio-economic areas is rejected. The socio-economic status of the school does not influence the perception of educators. It is, therefore, important to examine other possible influences. 
TABLE VI

PERCEIVED EFFECTIVENESS OF SUBSTITUTE TEACHERS

BY TYPE OF EDUCATOR AND IOCATION OF SCHOOL

\begin{tabular}{|c|c|c|c|c|c|c|c|c|c|}
\hline \multirow{2}{*}{$\begin{array}{l}1 / \\
\text { VARTABLES }\end{array}$} & \multirow[b]{2}{*}{ Group } & \multicolumn{2}{|c|}{$\begin{array}{l}\text { Administrators } \\
\mathrm{T}\end{array}$} & \multicolumn{2}{|c|}{$\begin{array}{l}\text { Regular } \\
\text { Teachers }\end{array}$} & \multirow{2}{*}{$\begin{array}{c}\text { T } \\
\text { Value } \\
\end{array}$} & \multicolumn{2}{|c|}{$\begin{array}{l}\text { Substitute } \\
\text { Teachers }\end{array}$} & \multirow{2}{*}{$\begin{array}{c}\text { T } \\
\text { Value } \\
\end{array}$} \\
\hline & & SD & Value $^{a}$ & $M$ & SD & & $\mathrm{M}$ & SD & \\
\hline \multirow[t]{2}{*}{ Substitutes Effective Educators } & 1 & $\begin{array}{l}4.67 \quad 1.13 \\
(n=24)\end{array}$ & .432 & $\begin{array}{l}5.04 \\
(n=24)\end{array}$ & 1.12 & $.046^{*}$ & $\begin{array}{l}5.26 \\
(n=23)\end{array}$ & 1.51 & \multirow[t]{2}{*}{.465} \\
\hline & 2 & $\begin{array}{l}4.61 \quad 1.34 \\
(n=28)\end{array}$ & & $\begin{array}{l}4.54 \\
(n=28)\end{array}$ & 1.00 & $2<1$ & $\begin{array}{l}5.30 \\
(n=20)\end{array}$ & 1.30 & \\
\hline \multirow[t]{2}{*}{ Substitutes Effective Educators } & 1 & $\begin{array}{l}-2.04 \\
(n=24)\end{array}$ & .390 & $\begin{array}{l}-1.50 \\
(n=24)\end{array}$ & 1.02 & $.014^{*}$ & $\begin{array}{l}-1.48 \\
(n=23)\end{array}$ & 1.41 & \multirow[t]{2}{*}{.167} \\
\hline & 2 & $\begin{array}{l}-2.14 \\
(n=28)\end{array}$ & & $\begin{array}{l}-2.18 \\
(n=28)\end{array}$ & 1.12 & $2<1$ & $\begin{array}{l}-1.05 \\
(n=19)\end{array}$ & 1.39 & \\
\hline \multirow[t]{2}{*}{ Substitutes Observe \& Evaluiate } & 1 & $-.76)^{1.33}$ & .121 & -.72 & .94 & \multirow[t]{2}{*}{.0515} & $\because 96$ & 1.36 & \multirow[t]{2}{*}{.159} \\
\hline & 2 & $\begin{array}{l}-1.21 \\
(n=28)\end{array}$ & & $\begin{aligned}= & 1.21 \\
& (n=28)\end{aligned}$ & 1.20 & & -.47 & 1.07 & \\
\hline \multirow[t]{2}{*}{$\begin{array}{l}\text { Substitutes Maintain Standards } \\
\text { of Behavior }\end{array}$} & 1 & $\begin{array}{l}-2.08 \quad 1.38 \\
(n=25)\end{array}$ & .238 & $\begin{array}{l}-1.28 \\
(n=25)\end{array}$ & 1.14 & $.007 *$ & $\begin{array}{l}-1.52 \\
(n=23)\end{array}$ & 1.34 & \multirow[t]{2}{*}{.239} \\
\hline & 2 & $\begin{array}{l}-1.791 .57 \\
(n=28)\end{array}$ & & $\begin{array}{l}-2.21 \\
(n=28)\end{array}$ & 1.50 & $2\langle 1$ & $\begin{array}{l}-1.22 \\
(n=18)\end{array}$ & 1.31 & \\
\hline $\begin{array}{l}\text { Substitutes Prepare Class/Room } \\
\text { for Next Day }\end{array}$ & 1 & $\begin{array}{l}-1.76 \\
(n=25)\end{array}$ & .366 & -.91 & 1.16 & .223 & 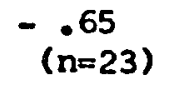 & 1.11 & .409 \\
\hline
\end{tabular}




\begin{tabular}{|c|c|c|c|c|c|c|c|c|c|}
\hline \multirow{3}{*}{$\begin{array}{l}2 / \\
\text { VARIABLES }\end{array}$} & \multicolumn{5}{|c|}{$\begin{array}{l}\text { TABIE VI } \\
\text { (continued) }\end{array}$} & \multirow{3}{*}{$\begin{array}{c}\mathrm{T} \\
\text { Value }^{\mathrm{a}}\end{array}$} & & & \multirow{3}{*}{$\begin{array}{c}\text { m } \\
\text { Value } \\
\end{array}$} \\
\hline & \multirow[b]{2}{*}{ Group } & \multicolumn{2}{|c|}{ Administrators } & \multicolumn{2}{|c|}{$\begin{array}{l}\text { Regular } \\
\text { Teachers }\end{array}$} & & \multicolumn{2}{|c|}{$\begin{array}{l}\text { Substitute } \\
\text { Teachers }\end{array}$} & \\
\hline & & SD & Value $^{a}$ & $M$ & SD & & $\mathbf{M}$ & SD & \\
\hline & 2 & $\begin{array}{l}-1.61 \\
(n=28)\end{array} 1.62$ & & $\begin{array}{l}-1.22 \\
(n=27)\end{array}$ & 1.60 & & $-\underset{(n=19)}{.58}$ & .90 & \\
\hline \multirow[t]{2}{*}{$\begin{array}{l}\text { Substitutes Correct Students } \\
\text { Work }\end{array}$} & 1 & -.831 .09 & .054 & $\begin{array}{l}-1.67 \\
(n=24)\end{array}$ & 1.56 & .341 & $-\underset{(n=23)}{.52}$ & .95 & \multirow[t]{2}{*}{.070} \\
\hline & 2 & $\underset{(n=26)}{-1.5} 1.73$ & & $\begin{array}{l}-1.48 \\
(n=27)\end{array}$ & 1.65 & & -16 & .50 & \\
\hline \multirow[t]{2}{*}{ Substitutes Keep Records } & 1 & $\begin{array}{l}-1.92 \\
(n=25)\end{array}$ & .409 & $\begin{array}{l}-1.72 \\
(n=25)\end{array}$ & 1.57 & .406 & -.83 & .94 & \multirow[t]{2}{*}{.457} \\
\hline & 2 & $\begin{array}{l}-1.82 \\
(n=28)\end{array}$ & & $\begin{array}{l}-1.82 \\
(N=28)\end{array}$ & 1.51 & & $-\underset{(n=19)}{.79}$ & 1.23 & \\
\hline \multirow[t]{2}{*}{$\begin{array}{l}\text { Substitutes Use Non-Teaching } \\
\text { Time }\end{array}$} & 1 & $\begin{array}{l}-1.96 \\
(n=24)\end{array}$ & .084 & $\begin{array}{l}-1.92 \\
(n=24)\end{array}$ & 1.61 & .269 & -.59 & 1.47 & \multirow{2}{*}{$\begin{array}{c}.0005 * \cdots \\
1<2\end{array}$} \\
\hline & 2 & $\begin{array}{l}-2.712 .11 \\
(n=28)\end{array}$ & & $\begin{array}{l}-2.29 \\
(n=28)\end{array}$ & 1.76 & & $-\underset{(n=19)}{.32}$ & .58 & \\
\hline \multirow[t]{2}{*}{$\begin{array}{l}\text { Substitutes Carry out Lesson } \\
\text { Plans }\end{array}$} & 1 & $\underset{(n=23)}{-1.22} 1.00$ & $.031 *$ & $\begin{array}{l}-1.60 \\
(n=25)\end{array}$ & 1.41 & .399 & $-\cdot 30$ & .77 & \multirow[t]{2}{*}{.479} \\
\hline & 2 & $\begin{array}{l}-1.86 \\
(n=28)\end{array}$ & 24 & $\begin{array}{l}-1.50 \\
(n=28)\end{array}$ & 1.42 & & -.32 & .58 & \\
\hline $\begin{array}{l}\text { Substitutes Should Prevent } \\
\text { Instructional Loss }\end{array}$ & 1 & $\begin{array}{c}-2.00 \\
(n=24)\end{array}$ & .388 & $\begin{array}{l}-1.96 \\
(n=24)\end{array}$ & 1.37 & .265 & $\begin{array}{l}-1.61 \\
(n=23)\end{array}$ & 1.68 & .064 \\
\hline
\end{tabular}




\begin{tabular}{|c|c|c|c|c|c|c|c|c|c|}
\hline \multirow{3}{*}{$\begin{array}{l}3 / \\
\text { VARIABLES }\end{array}$} & \multirow[b]{3}{*}{ Group } & \multicolumn{4}{|c|}{$\begin{array}{l}\text { TABIE VI } \\
\text { (continued) }\end{array}$} & \multirow{3}{*}{$\begin{array}{c}\mathrm{T} \\
\text { Value }^{\mathrm{a}}\end{array}$} & & & \multirow{3}{*}{$\begin{array}{c}\mathrm{T} \\
\text { Value }^{\mathrm{a}}\end{array}$} \\
\hline & & \multicolumn{2}{|c|}{ Administrators } & \multicolumn{2}{|c|}{$\begin{array}{l}\text { Regular } \\
\text { Teachers }\end{array}$} & & \multicolumn{2}{|c|}{$\begin{array}{l}\text { Substitute } \\
\text { Teachers }\end{array}$} & \\
\hline & & $S D$ & value $^{\mathrm{a}}$ & $\mathrm{M}$ & SD & & $M$ & $S D$ & \\
\hline \multirow{3}{*}{$\begin{array}{l}\text { Substitutes Create Learning } \\
\text { Environment }\end{array}$} & 2 & $\begin{array}{l}-2.11 \\
(n=28)\end{array}$ & & $\begin{array}{l}-2.21 \\
(n=28)\end{array}$ & 1.52 & & -.90 & 1.25 & \multirow{3}{*}{.189} \\
\hline & 1 & $\begin{array}{l}-1.00 \\
(n=24)\end{array}$ & .500 & $\begin{array}{l}-1.00 \\
(n=24)\end{array}$ & 1.35 & .334 & -.09 & .29 & \\
\hline & 2 & $\ln _{(n=28)}^{-100} 1.19$ & & -.85 & 1.09 & & -.20 & .52 & \\
\hline \multirow[t]{2}{*}{$\begin{array}{l}\text { Effectiveness (Average Score } \\
\text { Effectiveness) }\end{array}$} & 1 & $\underset{(n=25)}{-1.53} .81$ & \multirow[t]{2}{*}{.231} & $\begin{array}{l}-1.41 \\
(n=25)\end{array}$ & .80 & \multirow[t]{2}{*}{.142} & -.89 & .65 & \multirow{2}{*}{$\begin{array}{c}.0385 \\
1<2\end{array}$} \\
\hline & 2 & $\begin{array}{c}-1.73 \quad 1.05 \\
(n=28)\end{array}$ & & $\begin{array}{l}-1.65 \\
(n=28)\end{array}$ & .85 & & $\because(n=19)$ & .59 & \\
\hline
\end{tabular}

Group 1 = schools located in low sccio-economic areas according to Federal guidelines. Group 2 = Schools located in average and above average socio-economic areas.

a Shows the pairwise differences between groups 1 and 2, and the level of significance.

* $\mathrm{p} \leq .05 ; \quad * \mathrm{p} \leq .01 ; \quad * * \mathrm{p} \leq .001$ 
EXPLORATORY PROCEDURES

Due to the exploratory nature of this research, several procedures were used to explore more fully the nature of the relationship between role theory and substitute teachers effectiveness. These procedures are by nature exploratory, and less constrained by measurement limitations. They must anly be viewed as suggestions regarding the interrelationships presented in the role episode model.

The purpose of these exploratory procedures was to increase the understanding of the interrelationships among role senders, focal person and other factors that may be indirectly affecting the behavioral outcame by the focal person. This led to a closer examination of what the role episode model described as "other factors influencing the interpersonal process within the model". For example, within the substitute teaching services, administrative and supervisory practices are considered essential, according to the literature. Substitute teachers, the literature suggests, need supervision. The question was therefore asked: What is the relationship between administrative practices and substitute teachers' effectiveness?

The basic philosophy undergirding this question is that, given the substitute teachers' unfamiliarity with the total school system, the buildings, students, the rules, policies, and possibly the subject matter that they are asked to teach, supervisory help and guidance becomes a necessity. It seems that admiristrators would consider giving attention to these activities in order to facilitate the instructional goals of the building and the district. 
To answer this question, twenty-two variables relating to administrative roles, and practices were used. With these variables correlation procectures were used to show their relationship to effectiveness. (See Table VII).

Table VII shows that seven of the twenty-two variables are correlated significantly with effectiveness at the .01 level and three are significant at .05 . These variables can be grouped under one broad heading: - motivational activities. These activities range from giving substitute teachers encouragement to be resourceful in the classroom to providing them with the incentive to work with the prospect of being made full-time should they so choose; they include classroom climate and the inclusion of substitute teachers in the mainstream of school activities.

There are three items that deal specifically with the district's role in relation to the substitutes' effectiveness. They are (1) District's policies and practices should be an influential element in the determination of substitute's effectiveness, (2) the centralized system of operation should be used effectively, (3) an in-building substitute program for objective evaluation of the substitute teaching services. Although the correlations are not very strong, they suggest the need for some corrective measures to be taken to improve the substitute teaching services. 
TABIE VII

CORREIATIONS OF ADMINISTRATIVE PRACTICES

WITH SUBSTITUTE TEACHERS' EFFECTIVENESS ${ }^{+}$

\begin{tabular}{|c|c|c|}
\hline Administrative Practices & $r$ & $\mathrm{n}$ \\
\hline Substitutes encouraged to be resourceful & $.22 * \bullet$ & 144 \\
\hline $\begin{array}{l}\text { Substitutes' effectiveness measured by carrying } \\
\text { out regular teacher's lesson plan }\end{array}$ & $.22^{4 *}$ & 144 \\
\hline $\begin{array}{l}\text { Substitutes' effectiveness determined by length } \\
\text { of notice }\end{array}$ & -.01 & 138 \\
\hline $\begin{array}{l}\text { Evaluation based on type of information left } \\
\text { for substitute }\end{array}$ &.- .10 & 143 \\
\hline $\begin{array}{l}\text { Substitutes effective when assigned in } \\
\text { certified fields }\end{array}$ & $.20 *$ & 143 \\
\hline Favorable climate in the classroom & $.25 *$ & 141 \\
\hline Substitutes encouraged to do creative work & .09 & 141 \\
\hline Substitutes supervised for full-time service & $.21 * *$ & 141 \\
\hline Substitutes included in mainstream activities & $.26 *$ & 142 \\
\hline $\begin{array}{l}\text { Substitutes informed of professional growth } \\
\text { activities }\end{array}$ & .06 & 134 \\
\hline $\begin{array}{l}\text { Substitutes informed of changes in law affecting } \\
\text { education }\end{array}$ & .04 & 134 \\
\hline Substitutes encouraged to buy into retirement fund &.- .00 & 129 \\
\hline Substitutes have collective bargaining & -.05 & 133 \\
\hline $\begin{array}{l}\text { Substitutes discouraged from receiving unemployment } \\
\text { compensation }\end{array}$ & .10 & 126 \\
\hline $\begin{array}{l}\text { Administrators responsible for improving substitu } \\
\text { performance }\end{array}$ & $.24 * *$ & 139 \\
\hline $\begin{array}{l}\text { District's policies and practices determine substi } \\
\text { performance }\end{array}$ & $.18^{\bullet}$ & 140 \\
\hline District uses in-building substitutes &.- .07 & 144 \\
\hline Monitor students without substitutes & -.07 & 143 \\
\hline
\end{tabular}


TABLE VII

(continued)

Use resource centers without substitutes

$.12 \quad 143$

Administrators create learning environment

$.12 \quad 143$

In-building substitute program for objective evaluation

$.26 * 137$

Use centralized system

$.18 * 139$

+ Effectiveness score used was question 19B minus question 19A; the question was recoded for correct weighting of scale; also some individual scores were collapsed when calculating the effectiveness score (QI9RBMAC).

- $p \leq .05 \quad * p \leq .01$ two tailed test of statistical significance. 
A further exploratory procedure was done by comparing the mean scores of each of 22 items (Ideal and Actual) related to administrative practices. The "Ideal" was used to obtain what the educators perceived as desirable activities or interventions by administrators to enhance the cause of the substitute teaching services, while the "Actual" was used to ascertain what really occurred. The purpose of the procedure was to see how far apart or how close the perceptions of the "Ideal" and "Actual" really were, and to make some general observations about the data.

The results of this procedure are seen in Table VIII. It shows the means, standard deviations, and T-Values along with their significance levels. Two important observations can be made: First, there are 21 questions with significant differences between the mean of the "Ideal" and "Actual" scores $(p \leq .001)$ and one that is significant at the .05 level. Secondly, what this probably means is that the educators would like to see administrators at both district and building levels do more to make the "Actual" and "Ideal" come closer together. Although some of these items must be recognized as purely idealistic and probably not attainable within the foreseeable future (e.g., laws changed to leave students unsupervised in a resource center), there might be others such as providing substitutes with professional growth information that will be helpful, and could be implemented inmediately.

The implication of this exploration then is not so much what was done through administrative practices and policies, but what was not done that might have motivated the substitutes to be more 
Comparison of Means, Standard Deviations, and T-Values for items related to Administrative Practices - Ideal and Actual.

$1 /$

Substitutes should be encouraged to be resourceful

$6.24 \quad 1.13$

Substitutes are encouraged to be resourceful

$\begin{aligned} & 4.24 \\ & (n=147)\end{aligned} \quad-12.85 * \cdots$

Substitutes' effectiveness should be measured by carrying out of teachers' lesson plan

$5.47 \quad 1.56$

Substitutes' effectiveness is measured by carrying out teachers' Iesson plan

$\underbrace{4.62}_{(n=146)} 1.67 \quad-4.84 * * *$

Substitutes' effectiveness should be measured by length of notice

$3.54 \quad 1.94$

Substitutes' effectiveness is measured by length of notice

2.86
$(n=140)^{-4.09 * * *}$

Substitutes effectiveness should be measured by information left by regular teachers
6.121 .30 $-10.62 * \cdots$
$4.36 \quad 1.77$ $(n=145)$

Substitutes are measured by information left

Substitutes should be effective when assigned in their own field

$6.32 \quad .09$

Substitutes are effective when assigned in their own field

$\underset{(n=145)}{6.13} .09^{-2.01 *}$

Favorable climate should exist in the classroom

$6.8 \quad .62$
$5.06 ; 1.30 \quad-13.86 * * 1$
$(n=142)$

Substitutes should be encouraged to do creative work

5.901 .30
$3.64 \quad 1.46 \quad-15.46 * \ldots *$
$(n=143)^{-*}$


TABIE VIII

(continued)

2/

ITEMS

M SD T-VALUES

Substitutes should be evaluated for full-time jobs

$5.73 \quad 1.62$

Substitutes are evaluated for fulltime jobs

$$
\begin{aligned}
& 3.33 \\
& (n=144)^{1.39}
\end{aligned}
$$

Substitutes should be included in school's activities

$4.32 \quad 2.02$

Substitutes are included in school's activities

$\begin{array}{ll}2.78 & -8.72 * * \\ (n=145)^{1.48} & \end{array}$

Substitutes should be provided with professional growth information

$6.27 \quad 1.01$

Substitutes are provided with professional grouth information

$3.60 \quad 1.55 \quad-16.37 * * *$
$(n=137)^{-*}$

Substitutes should be provided with educational changes in the law

$\begin{array}{lll}6.54 & .75 \\ 3.58 \\ (n=137)^{1.50} & -10.96 \ldots *\end{array}$

Substitutes should be encouraged to buy into retirement fund

$4.97 \quad 1.66$

Substitutes are encouraged to buy into retirement fund

$\begin{array}{lll}3.70 & 1.43 & -7.08 * * * \\ 5.31 & 1.76 & -9.32 * * * \\ 3.59 & 1.45 & \end{array}$

Substitutes should be discouraged from unemployment compensation

\section{$4.59 \quad 1.24$}

Substitutes are discouraged from unemployment compensation

$3.46 \quad 1.58 \quad-6.06 * * *$
$(n=128)^{1.4}$

Administrators should help improve substitutes' performance

$5.01 \quad 1.85$

Administrators do help improve substitutes' performance

$3.40 \quad 1.62$ 


M SD T-VALUES

District policies should influence substitutes performance

District policies do influence substitutes performance

$\begin{array}{lll}5.62 & 1.44 \\ 4.04 & & -10.59 * 2 * \\ (n=143)^{-52}\end{array}$

District should use building faculty as substitutes

$5.97 \quad 1.83$
$\begin{aligned} & 4.33 \quad 1.60 \\ & (n=145)^{-8.98 * * *}\end{aligned}$

Students should be monitored without substitutes

$5.89 \quad 1.70$

Students are monitored without substitutes

4.99
$(n=145)^{-4.78 * * *}$

Should use libraries, etc., without substitutes

$5.94 \quad 1.50$

Do use libraries, etc., without substitutes

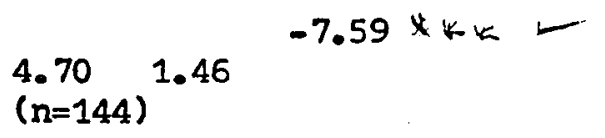

Administrators should create a favorable learning environment

$6.29 \quad 1.30$

Administrators do create a favorable learning environment

$$
\begin{aligned}
& 5.27 \quad 1.30 \quad-8.86^{* * *} \\
& (n=143)^{-}
\end{aligned}
$$

In-building substitute program should be initiated
$4.35 \quad 1.94$
$9.921 .62^{-6.83 * \cdots}$
$(n=138)$
$5.72 \quad 1.38$

$5.19 \quad 1.70 \quad-3.82 * \cdots$

In-building substitute program is in operation

Centralized substitute teaching services should be effective

Centralized substitute teaching services is effective

$p \leq .05 ; \quad * 0 p \leq .001$ 
effective educators. What effect these deeds of onmissions have on the role episode model cannot be directly ascertained; it can only be assumed that substitutes need more help from administrators.

\section{Summary of Results}

There were three hypotheses tested. The results show that there is no role conflict in the substitute teaching services. Administrators, regular teachers, and substitute teachers appear to agree on those tasks that can be identified as the substitute teachers' role.

Role ambiguity does exist. Not only do substitute teachers perceive their role to be under-defined but administrators and regular teachers also have similar perceptions. The areas of ambiguity are not identified; the results indicate, however, that role clarity is absent. The location of the workplace does not affect the perception of the educators. Personnel of Chapter 1 schools perceived substitutes in the same way as personnel in nonChapter 1 schools.

The exploratory questions were used as a partial check on the conceptual model. The model suggested that there were interpersonal factors that might influence the role outcome. The results demonstrate that there are possible moderating variables that are influencing the relationship between ambiguity and effectiveness. These include motivational factors such as rescurcefulness, job incentives, and involvement in classroom decisions. The organizational factors include communication and innovation. Administrators need to become more involved in the substitute teaching services. 
CHAPTER V

CONCLUSIONS

This research has explored the ways in which role conflict and role ambiguity are associated with substitute teacher effectiveness. It also examined the affect of the socio-econanic status of the workplace on the perceptions of educators regarding substitute teacher effectiveness.

Five specific research questions were asked, and three hypotheses were stated.

1. To what extent, if any, is there an inter-sender role conflict? Or, do administrators and regular teachers have a common view regarding the role of the substitute teacher?

2. To what extent, if any, is there focal person-sender role conflict? Or, do substitute teachers perceive their role differently from administrators and regular teachers?

3. According to substitute teachers is there ambiguity regarding their work?

4. What is the relationship between the perceptions of educators regarding what should be done within the substitute teaching services and what is actually done? And

5. According to administrators, regular teachers, and substitute teachers, what factors contribute to effective substitute teaching. 
Three hypotheses were tested. They were:

1. The role expectations held by substitute teachers by regular teachers and administrators are different from those held by the substitute teachers themselves.

2. The more ambiguous substitute teachers perceive their role, the less effective they will consider themselves in the classroom.

3. The performance of substitute teachers in non-Chapter I schools is more positively perceived by all groups of educators than that of substitute teachers in Chapter I schools.

Both statistical and descriptive analyses have been used to answer these questions and to explore the hypotheses regarding role clarity and effectiveness. Role conflict, ambiguity and effectiveness measures were operationalized to measure the influence of role clarity on performance; and analysis of variance and other statistical procedures were used to analyse the data. In addition, descriptive analyses of role characteristics and effectiveness characteristics were done to explain educators perception of what factors contribute to effective substitute teaching. This concluding chapter discusses the relevance of these findings to administrative policies and practices within the education system. 
THEORETICAL TMPLICATIONS OF THE RESEARCH

This research presents support for a number of theories and concepts found in the literature on role theory as it relates to the substitute teaching services. The research also has implications for administrative poldcles and.practices. It confirms the work of Kahn, Wolfe, Sncek, and Rosenthal (1964) which states that role conflict and role ambiguity are partially a function of a complex interaction of job content, leader behavior, and organizational structure.

Two directions of research based on role theory are:

(a) role conflict and (b) role ambiguity. With regard to the first direction concerning inter-sender role conflict, it is important to point out that the results of this study are in keeping with the results of previous research findings relating to role conflict (Rizzo et al 1970). There was very little role conflict found between the administrators and regular teachers. It appears that for the most part there is a cormon understanding of what is the role of substitute teachers. Both groups of educators seem to agree that the general intent of all substitute teaching is to facilitate instructional continuity. Thus, it is no surprise when, on a scale of 1-7, the two educational groups scored high in response to the question, "Should substitute teachers serve the purpose of preventing instructional loss to students?" $(M=6.50$ and 6.45$)$. 
However, it is important to remember that role is defined as a set of prescriptions defining what the behavior of a position member should be (Biddle \& Thomas, 1966, p.20). While there is relative agreement on what the role should be, it is quite the opposite to what is perceived as being accomplished. Could the problem of role then be in the focal person-sender relationship? The second research question examines this problem.

The question is, "is there focal person-sender role conflict? Or, do substitute teachers perceive their role differently from administrators and regular teachers?" This question was posed as a hypothesis; it postulated that substitute teachers would view their role differently. The data did not support this hypothesis which means that when substitute teachers take over the classroom of regular teachers, although the substitutes sub-goals for the day may be different from those of the regular teachers, their overall goal remains the same. The first goal of the substitute teacher is to get to the appointed school, find the classroom, orient themselves to the building, the program, and to the students' reaction to the fact that they have a substitute for that day. The substitutes' success in dealing with the students' needs and concerns depends on their ability to carry out the regular teacher's lesson plan and to assert themselves as the regular teaciner would as "the one in charge".

It must be noted that while substitutes sense some responsibility for creating an atmosphere of learning in the classroom, they are not as positive about that role as the regular teachers and administrators. What this probably means is that the substitutes expect the regular classroom teachers to create an atmosphere 
conducive to learning, so that the substitute's role in this regard would be a shared responsibility rather than a total responsibility. The preparedness of a teacher and classroom management seem to go hand in hand. When substitutes are uncertain about the subject matter cue to the fact that they are asked to teach a subject outside their field of specialization, or that they were not given enough time to prepare the lesson, behavior problems in the classroom are likely to increase. The behavior might be simple indifference on the part of students who by such behavior create a negative pattern that must be broken if appropriate learning conditions are to be restored. To help break these patterns, indeed, to prevent these problems from developing, regular teachers need to prepare their classes much better for the presence of their substitutes, and administrative supervision needs improving to assist substitutes in the sheer logistics involved. If the regular teacher leaves a film for the substitute teacher to show, that is simple enough; except that if the projector is not in the classroom, or if the sound-bulb blows, several minutes could be wasted in locating the equipment which means several minutes of instruction lost. To preserve the continuity principle, greater supervision will have to be provided by administrative or supervisory personnel.

How does all this apply to the role episode model? The explanation lies in the relationship of those variables explaining the substitutes' perceptions of their role. While these variables do not affect the role episode directly, they do have an indirect influence on it. Substitutes who must be pre-occupied with the logis- 
tics of securing equipment to teach a subject outside of their field, with little or no time to prepare can only be concerned with their survival and not with the noble goal of instructional continuity. Instructional continuity pre-supposes that the substitute teacher and the regular teacher have similar conditions to work under. The data show that substitutes do not see it quite that way. The data seem to suggest that the conflict stems partially from the complex interaction of job content, administrative supervision, or lack of it, and the organizational structure of the substitute teaching services.

The second component of role theory is role ambiguity. To answer the question of the relation of role ambiguity to effectiveness, data were collected on ambiguity and effectiveness, and correlation procedures were used to test the relationship. The data supported the hypothesis that the greater the ambiguity, the less effective substitute teachers will perceive themselves. The findings of this study are consistent with the research findings in other fields. Even if role conflict is absent, role ambiguity is usually present.

This suggests that the ineffectiveness that has been ascribed to substitute teachers may not he so much a question of effectiveness or ineffectiveness, but rather a question of role clarity. The characteristics of role ambiguity include the degree to which clear information is lacking regarding the expectation associated with a role, and methods of fulfilling those known role expectations. The data regarding role expectations show that the 
substitutes are aware of the expectations associated with their role. In fact, the data show that substitutes were much more positive about what their role is than were the administrators and regular teachers. It is conceivable then, that the role became ambiguous when the methods of fulfilling those role expectations were neither clear nor, in sone cases, articulated. Hence, substitutes are often left floundering and are expected to "do the best tiey can". As was pointed out earlier, Khan's role episode model is confirmed. The role episode becomes confused by the influences of other variables that affect it negatively. In some cases the influence might have come from the very structure of the substitute teaching services, while in other cases it might have been the sheer impracticality of effecting instructional continuity without an adequate lesson plan from the regular teacher.

But the role episode model suggests that role ambiguity is derived not only from lack of clear instructions, but also from other mediating variables that influence the total interpersonal process. In the case of the substitute teaching services a very important variable seems to be the role of administrative and supervisory practices. 
IMPITCATIONS FOR EDUCATIONAL AND ADMTNISTRATIVE

POLICIES AND PRACTICES

Fran the standpoint of policymakers in the field of education, this research can provide certain tentative answers to their questions regarding how to improve the substitute teaching services. The data indicate that role conflict is not a problem at this time. It is important, however, to always have clearly stated job descriptions for substitute teachers. From the data it appears that while no differences exist regarding role identification, there are tasks associated with the role on which there needs to be specific instructions telling substitute teachers to what degree they can use flexibility and depart from the instructional continuity principle. If, for example, the lesson plan calls for a discussion on "The Romantic Movement in Iiterature," specific alternative lesson plans may be provided to give the substitute a clear chojce of lesson to teach, without violating the continuity principle.

The data regarding ambiguity indicate the need to address classroom management matters. Such as maintaining standards of behavior, preparing the class for the next day's work, and keeping accurate record. This is probably the area in which administrators or supervisors can help to improve the substitute teaching services by providing the direct support service the substitutes need. Although these services can be provided more directly when in-building administrators have greater control of the recruiting, training, and evaluating of 
substitute teachers, a reasonable amount of service can still be done under existing organization and structure to help substitute teachers.

The structural arrangements might have to be examined, however, to deal with such problems of short notices to report for an assignment. The data indicate that there is a significant relationship between the central office's arrangements for delivering substitute service to the schools and the effectiveness of substitute teachers. The central office system might need upgrading for another reason: to deal with the problem of misassignment. This factor might be one of the most dubious elements in the role episode, and the most negative factor in carrying out the continuity principle. The element of ambiguity is evident and needs to be addressed by administrators and other policy makers.

RECOMMENDATIONS

On the basis of the findings and conclusions of this study, it is recommended that, in order to reduce or eliminate role ambiguity in the substitute teaching services, administrators, regular teachers and substitute teachers need to address the following:

(1) Develop an on-going line of communication and training between all three groups of educators, through staff 
development programs. This interaction must not be limited to an exchange of notes between regular teachers and substitute teachers, or between administrators and substitute teachers about the day's activities in the classroom. Rather, they should be formal sessions designed for the mutual enhancement of the educators themselves and of the profession in general. Professional Day activities and motivation seminars would be a good way to start.

(2) Make plans for more direct supervision of substitute teachers. Administrators may delegate this responsibility to the department heads who can provide the information and assistance to the substitute teacher regarding instructional materials and equipment at a moment's notice, and also offer invaluable advice to improve the substitutes' performance.

(3) Evaluate the structure and operation of the substitute teaching services periodically to determine its responsiveness to the need of the people it is designed to serve, and to check its effectiveness in meeting that need. Its practices should be compared with current findings in the literature and research.

(4) Prepare students to serve as a support system to substitute teachers through such means as substitute teacher aides, and generally to curb certain student activities such as checking out of class to do a library assignment. Offer incentives to students to be positive and give appropriate recognition for their efforts. 
(5) Substitute teacher organizations need to be much more aggressive in articulating substitutes' needs, selling their ideas, and improving the status and image of their members. Every member should make it a goal to professionalize their work, and to help others to perceive it in that light.

\section{NEEDS FOR FURTHER RESEARCH}

A major limitation of this research is its lack of universal application. One area of further research would be to replicate the study with a more broad-based and representative sample. Such expanded studies are both cost prohibitive and time consuming. In any event, a better cross-section of educators, probably representing a region, should be used to give the study a broader application. Until such replication occurs the results of this study must be accepted with caution.

Another limitation of this research is that it lacks a rich theoretical basis on which to draw. Literature abounds on role conflict and role ambiguity, but very little deals with how these variables relate to education, and none deal specifically with how they relate to the substitute teaching services. Therefore, any further study on the substitute teaching services might contribute greatly to knowledge, and would have a substantial theoretical base from which to draw if such study focuses on another related issue such as instructional loss within the substitute teaching system. In other 
words, rather than making instructional loss a single item in the questionnaire, the problem should focus around the amount of instructional time lost by operating within the existing organizational structure of the substitute teaching services. It is recognized that this is not a replication of the current study but it is hoped that this study will inspire many off shoots from it.

The present research was exploratory both in terms of the questions asked and the methods used to analyze the data. It would be desirable to have further methodological development in regard to the operationalization of the variables, and to the reliability and validity of the ratings used to measure ambiguity, conflict, and effectiveness. A first step in this direction would be to have an instrument more finely tuned with questions to measure conflict, and ambiguity and their relationship to effectiveness. It would be also useful to have a moderating variable to tell whether conflict/ambiguity is directly related to effectiveness or whether conflict/ambiguity is related to effectiveness when another condition exists. It is possible that such an improved instrument would strengthen the conclusions of this exploratory research, or alter the conclusions that could be drawn. 


\section{SUMMARY}

It is apparent from the literature and from the current practices in the substitute teaching system that there is a need for policy makers to reassess the role and effectiveness of substitute teachers. The reassessment seems particularly necessary in several ways. The way instructions are given to substitutes needs to be examined, whether they are fram the central office, the administrators in the building or the classroom teacher. This is a necessary approach to determine the area of ambiguity and role conflict.

It is also necessary for policy makers to re-examine their recruiting, assigning and evaluating of substitute teachers. If the system operates on the availability of substitutes, it will be constantly plagued with the problem of misassignment and limited notice. This in turn will affect the way substitutes can carry out the regular teachers' lesson plans which all groups of educators seem to agree is a worthwhile goal.

Perhaps more fundamental, but not very obvious, is the fact that the school system is a "loosely coupled system" in which substitute teachers function independently of administrators supervision. They presumably cherish their professional freedom and their sense of autonomy. But given the growing need for administrators to supervise substitute teachers, and to assist them in their professional growth, the policy makers might find it desirable to explore the development of a substitute teaching service with an independent and yet collaborative focus. 
At the outset of this research study it was thought that a redefinition of the role of substitute teachers was desirable. The results show, however, that what is needed is not a redefinition of the role but a clarification of the tasks related to that role. clear instructions of what to do, and the means by which to have clearly identifiable tasks done will improve the substitute teachers effectiveness substantially. In the long run, effective substitutes are bound to aid in the improvement of schools and the achievement of students in the classroom. 
REFERENCE BIBITOGRAPHY

Abbott, Max G., and Jahn T. Lovell, Eds., "Change Perspectives in Educational Adninistration," School Education, Auburn University, Atlanta: 1965, pp. 42-53

Bear, David E., and Regan Carpenter, "Substitute Teaching Programs," American School Board Journal, 143:16, Nov. 1961.

Benthul, Herman F. "Upgrading the Substitute Program," The Instructor, 73, (Sept., 1963).

Biddle, B. J., \& Thomas, E. J., (Eds.). Role Theory: Concepts and Research. New York: Wiley, 1966.

Bruno, James "Contributing to the Harms of Racial Isolation: Analysis of Requests for Teacher Transfers in a Iarge Urban School District." Educational Administration Quarterly's, Vol. 17, pp. 93-108, Spring. 1981.

Bruno, J. E. "On Staffing Inner City Schools." Phi Delta Kappan, 63 (8), 534-535, 1981.

Carr, Rey and Kathleen E. Ryan. "Rooty-Toot-Toot, Here Comes the Substitute", Interchange, 5, 1974

Dawson, Judith A., "Teacher Participation in Educational Innovation: Some Insigints into 1ts Nature. Philadelphia: Research for Better Schools, Inc., 1981.

Durn, Rita S., and Kenneth J. Dunn, "Learning Styles/Teaching Styles: Should They....Can They....Be Matched? Educational Ledership, Jan. 1979.

Eckstein, Max A., Schooling in Big Cities: A Comparative, International Perspective, Michigan State Curriculum Cormittee on Better Human Relations, 1978.

Education Research Service, Circular \#4, 1962.

Elliot, Peggy G., "Where are the Students? Student and Teacher Absenteeism in Secondary Schools", Vlewpoints in Teaching Spring, 1979.

Elsbree, William S., and Edmund E. Reuter, Staff Personnel in the Public Schools, Englewood Cliffs, New Jersey: Prentice-Hall, Inc., 1970, p.159. 
ERIC Clearing House on Educational Managenent, Merit Pay, Research Action Brief Number 15. Eugene, Oregon: University of Oregon, 1981.

ERIC Clearing House on Educational Management, Teacher Motivation, Regearch Action Brief Number 13. Eugene, Oregon: University of Oregon, 1980.

Erlandson, David A., and Pastor, Margaret C., "Teacher Motivation, Job Satisfaction and Alternatives - Directions for Principals." NASSP Bulletin, 1965, 442, Feb. 1981.

ERS Report, Practices and Procedures in the Use of Substitute Teachers, Education Research Service, 1977.

Fischer, Barbara Bree, and Louis Fischer, "Styles in Teaching and Learning," Educational Leadership, January, 1979.

Freedman, Mrian K., "The New Substitutes: Free to Teach!" NASSP Bulletin, May, 1975.

Futrell, Charles M., and a Parasuraman, "Impact of Clarity of Goals and Role Perceptions on Job Satisfaction" Perception and Motor Sk1118, 1981.

Gordon, Edmund W., "Toward a Conceptualization of Urban Education", Columbia University, New York, Erlc Clearinghouse on The Urban Disadvantaged. 1978.

Graen, G., "Role-Making Processes within Complex Organlzations." In M.D. Dunnette (Ed.), Handbook of Industrial Organizational Psychology. Chicago: Rand McNally, 1976.

Gregorc, William, "Learning Styles", Educational Leadership, Jamuary, 1979.

Gross, Neal, Howard Mason, and Alexander W. McEachern, Explorations in Role Analysis, New York, John Wiley \& Sons, 1958.

Hamner, W. C., \& Tosi, H. L. "Relationships of role conflict and role ambiguity to job involvement measures". Journal of Applied Psychology, 1974, 59, 497-499.

Heckman, David Lee, "A Study of Practices Related to the Recruitment, Selection, Assignment, Supervision, and Evaluation of Substitute Teachers in the Haverford Township Scheo? DAstrict, Haverford, Pennsylvania." Dissertation Abstracts. 31, 1971.

Ivancevich, J. M., \& Dannelly, J. H., "A study of role clerity and need for clarity for three occupational groups." Acaderny of Management Journal, 1974, 17, 28-36. 
Jacobson, Dugene, W. W. Charters, Jr., \& S. Uleberman, "The Use of the Role Concept in the Study of Complex Organization," Journal of Social Isoues, VII, 3 1951, pp. 18-27.

Kahn, R., Wolfe, Du, Quinn, R., Snoek, J., \& Rosenthal, R., Organizational Stress: Studies In Role Conflict and Ambiquity. New York: WIley, 1964.

Katz, D., \& Kahn, Rc In, The Social Psychology of Organizations. New York: W1ley, 1966.

Keller, Robert T. \& Szllagyl, Andrew D., "A Longetudinal Study of Leader, Reward, Behavior, Subordinate, Expectancies, and Satisfaction. Personnel Psychology, 1978, (Spring), ;01. 31, pp. 119-129.

Kerlinger, Fred N., Foundations of Behavioral Research. New York: Holt, Rinehart and Winston, Inc., 1964.

Iinton, Ralph, The Cultural Background of Personallty, New York: D. Appleton - Century Co., 1945.

Iinton, Ralph, The Study of Man, New York: D. Appleton - Century Co., 1936.

Locke, E. A. "Toward a theory of task motivation and incentives." Organtzational Behavior and Human Performance, 1968, 3, pp. 157-189.

Lyons, T., "Role clarity, need for clarity, satisfaction, tension, and withdrawal". Organizational Behavlor and Human Performance, 1971, 6, pp. 99-110.

Manlove, Donald C., and Peggy Elliot, "Absent Teachers....Another Handicap for Students," The Practitioner, Vol. V, No. 4, NASSP, 1979.

Mertan, Robert $K_{.}$, \& Robert A. Nisbet, Contenporary Social Problems, Harcourt, Brace and World, Inc., New York, 1961.

Merton, Robert K., Sociological Ambivalence and Other Essays. The Free Press, New York, 1976.

Merton, R., Social Theory and Social Structure, 2nd ed., Glencoe, IIIInois: Free Press, 1957.

Miles, R. H., "An empirical test of causal inference between role perceptions of conflict and amblgulty and varlous personal outcomes." Journal of applied Psychology, 1975, 60, 334-339.

National Education Association Research Bulletin, 33, Feb., 1955: 57. 
National Education Association Research Bulletin, 1955.

National Education Association, Today, 1983.

Nickerson, Neal C., Jr., "The Selection and Utilization of Substitute Teachers", Ed. Research and Dev. Council of the Twin Cities Metropolitan Area, Inc., 1965.

Nirenberg, John, "The Evolution of Organizational Theory and Its Application to Public Schools". NASSP Bulletin No. 62, January - May 1978.

Olson, Martin N., "Identifying Quality in School Classrooms: Some Problems and Some Answers". Central Ideas, 21, Feb., 1971.

Oregon Statement of competent and Ethical Performance Standards, 1979.

Parsons, Talcott, The Social System, Glencoe: The Free Press, 1951, pp. 38-39.

Parsons, Talcott, "Suggestions For a Soclological Approach to the Theory of Organizations - I" Adninistrative Sclence Quarterly, I, 1956, pp. 63-85

Passow, A. H. "Urban Education: The New Challenge". Paper Presented at the Annual Meeting of the American Educational Research Association, New York, 1977.

Porter, Andrew C., John R. Schwille, Robert E. Floden, Danald J. Freeman. "Teacher Autancony and the Control of Content Taught." Research Series \#24, Michigan State University, 1979.

Portland Public Schools, Chapter 1 Handbook. 1980.

Portland Public Schools, District-wide Teacher Evaluation Guide, 1979.

Rizzo, J. R., House, R. J., and Ifrtzman, S. I., "Role conflict and ambiguity in complex arganizations". Adninistrative Sclence Quarterly, 1970, 15, 150-163.

Rogers, D. L., and Molnar J. "Organizational antecedents of role conflict and ambiguity in top-level administrators". Administrative Science Quarterly, 1976, 21, 598-610.

Rogus, Joseph, and Matczynski, Thomas, "Principal-Central Office Communication", NASSP Bulletin, 61, 405, Jan., 1977, pp. 47-54.

Rosenthal, R., and Jacobsen, I., Pygmalion in the Classroom, New York: Holt, Rinshart and Winston, 1969.

Sarbin, Theodore R., "Role Theory" in Gardner Lindzey (Editor), Handbook of Social Psychology, Vol. I, Cambridge: Addison, Wesley Publishing Company, 1954. 
Sargent, Stansfeld, "Concepts if Role and Ego in Conteaparary Psychology", in John $H_{0}$. Horner and Muzafer Sherlf (Editors) Soctal Paychology at the Crossroads, (New York: Harper and Brothers, 1981.

Schuler, R. S., "The effects of role perceptions on employee satisfaction and performance moderated by employee ability". Organizational Bahavior and Human Performance, 1977, 13, 98-107.

Schuler, R. S., Aldag, R. J., and Brief, A. P., "Role conflict and mbiguity: A scale analys18". Organtzational Behavior and Human Performance, 1977, 20, 119-128.

Sorokin, Pitirim A., Society, Culture, and Persanality, New York: Harper, 1947.

Tosi, H. "Organization stress as a moderator of the relationship between influence and role response". Academy of Management Journal, 1971, 14, 7-20.

Urbanicity and Urban Education: A New Look; Annual Superintendents Work Conference, Teachers College, Columbia University, 1977.

Van Sell, M., Brlef, A. P., Schuler, R. S., "Role Conflict and Role Ambiguity: Integration of the Iiterature and Directions for Future Research. Human Relations, Vol. 34, No. 1, 1981, 43-71.

Waldo, Dwight, The Adninfstrative State, Ronald Press, New York, 1948.

Wayne, Marck C., "The Grooming of an Able Substitute." School Executive 78 (May 1959)

Weber, Max, "Bureaucracy", in Joseph A. Litterer (Ed.), Organizations: Structure and Behavior, New York: John wiley \& Sons, Inc., 1963, p. 45

Wiley, D. E., \& Harnischfeger, A., "Explosion of Myth: Quantity of schooling and exposure to instruction, major ecucational vehicles. Educational Researcher, April 1974, 7-12.

Wotherspoon, Paul C., Administratian of Substitute Teacher Services at the County District Level in the State of Ohio. Ann Arbor, Michigan, 1977. 
APPENDIX A

LETTER REQUESTING HIGH SCHOOL PARTICIPATION IN THE STUDY 
May 1982

Dear

As a classroom teacher in the Portland Public Schools, I have experienced concern over the instructional program in classes that must be taught by substitute. teachers in the absence of the regular teacher. This concern is shared by many educators.

I am currently working on a study designed to improve the substitute teaching services in the high schools of the Portland School District and I sincerely wish to include a sampling of administrators and teachers from your building in the study. The study is being conducted under the direction of Dr. Jerry Lansdowne of the School of Urban Affairs at Portland State University, and has the endorsement of Dr. Victor Doherty, Assistant Superintendent in charge of Evaluation for the Portland School District.

The questionnaires will be enclosed and will be placed in the teachers' and administrators ' boxes with instructions to leave the completed questionnaire with the secretary.

At the conclusion of the study, a copy of the findings will be given to all administrators participating and to others who are interested.

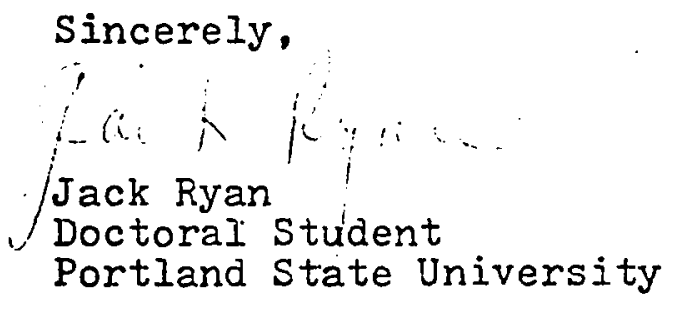


APPENDIX B

COVER IETTER ENCLOSED WITH SURVEY PACKETS 
Nay 1982

Dear Educator,

As you are well aware, teachers have to be absent from their classes from time to time in order to attend conferences, to be on jury duty, or because of illness. As a professional educator you are concerned about a continuous instructional program in the classroom during the regular teacher's absence. However, you are not sure what degree of instructional loss occurs, if any, what causes the loss, what should be done to correct it, and by whom.

Your participation in this study will help to provide some of the answers to these questions. The Portland School District has endorsed this study recognizing the importance of the research. I would appreciate, therefore, if you would now take a few minutes of your time to read the questions on the attached questionnaire and respond to them as objectively as you can. No names of schools, administrators, or teachers are to appear on the questionnaire and no such information will be released.

The results of this study will be shared with you for your educational benefit and the benefit of the students you serve.

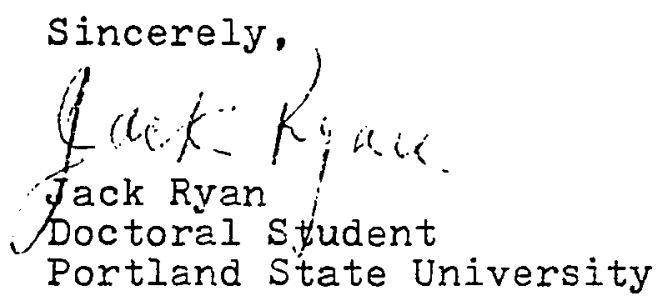


APPENDIX C

INSTRUCTIONS FOR COMPIETING QUESTIONNAIRE 
INSTRUCTIONS 1. All of the following questions pertain to the services of the Portland School District.

2. "Substitute teacher" means short-term substitute teacher for a day or two.

3. The questionnaire scale ranges from one through seven, and a mid-point, four, that shows you have no opinion on that question.

Examples:

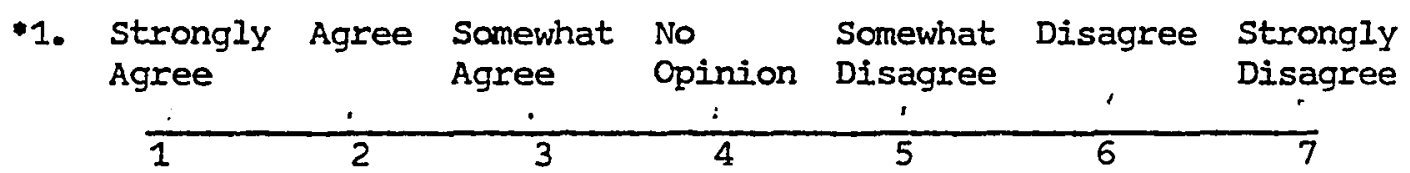

$\begin{array}{lllcc}\text { 2. To a } & \text { Most Many } & \text { No } & \text { Occasion- Seldom } & \text { Not at } \\ \text { Great } & \text { of the Times } & \text { Opinion } & \text { ally } & \text { All } \\ \text { Extent } & \text { Time } & & & \end{array}$

\begin{tabular}{lllllll}
\hline 1 & 2 & 3 & 4 & 5 & 6 & 7
\end{tabular}

4. Select the response that best describes your opinion by circling the appropriate number.

5. Do not write your name on the questionnaire. When you have completed the questionnaire, place it in the envelope provided and give it to the head secretary.

Thanks for your cooperation!

*For correct weighting of scales, numbers were reversed when placed in computer. 
APPENDIX D

QUESTIONNAIRE 
1. The role of short-term substitute teachers is clearly defined.

In your opinion, is the role of substitute teachers in this district clearly defined?

2. The role of the short-term substitute teacher should be "custodial".

In your opinion, is the role of the substitute teacher in Portland principally a custodial function?

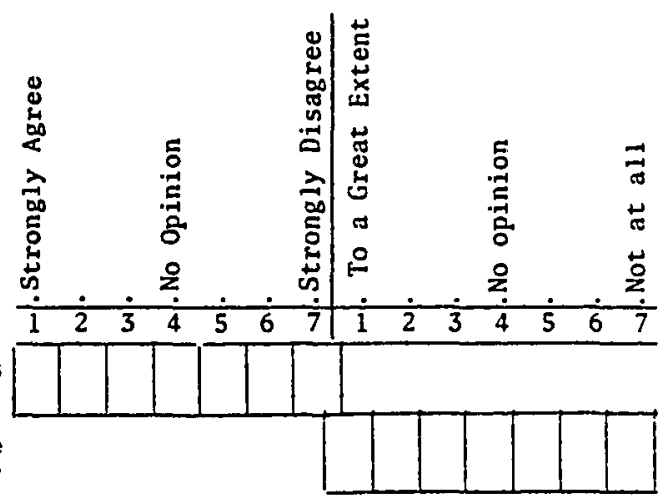

3. The role of the short-term substitute teacher should be one of guest teacher. (Guest teacher is defined as one who takes the classroom of a regular teacher but uses his/her own lesson plan.)

In your opinion, is the role of the substitute teacher in this district principally one of guest teacher?

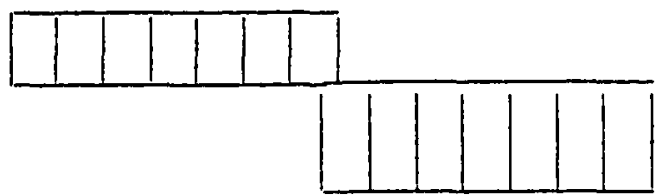

4. The substitute teacher should play a major role in the classroom by observing and evaluating student behavior for the regular teacher.

In your opinion, does the substitute teacher observe and evaluate student behavior for the regular teacher?

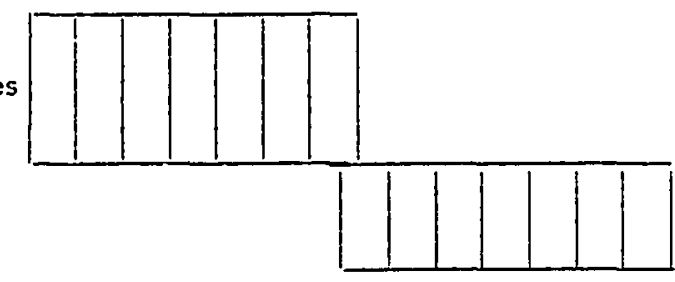

5. Substitute teachers should be encouraged to be resourceful in the classroom.

In your opinion, are substitute teachers encouraged to be resourceful in the classroom?

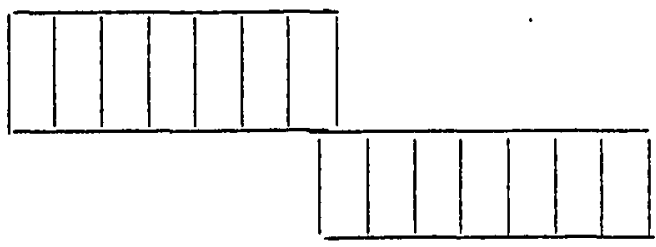

6. Standards of behavior established by the regular teacher should be maintained by the substitute teacher.
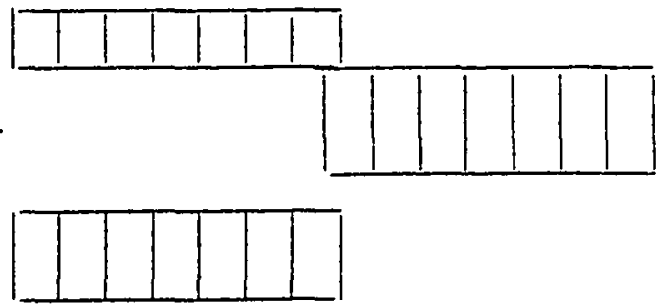


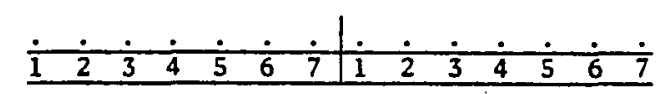

In your opinion, do substitute teachers maintain the regular teacher's standard of behavior?

7. The class and classroom should be prepared by the substitute teacher for the next day's work.

In your opinion, do substitute teachers prepare the class and classroom for the next day's work?

8. Substitute teachers should correct students' papers and make entries in the grade book.

In your opinion, do substitute teachers correct students' papers?

9. Substitute teachers should keep accurate records, e.g. grades, attendance, dates on matters needing attention.

In your opinion, do substitute teachers keep accurate records?

10. Substitute teachers should use nonteaching time to help individual students.

In your opinion, do substitute teachers use non-teaching time to help individual students?
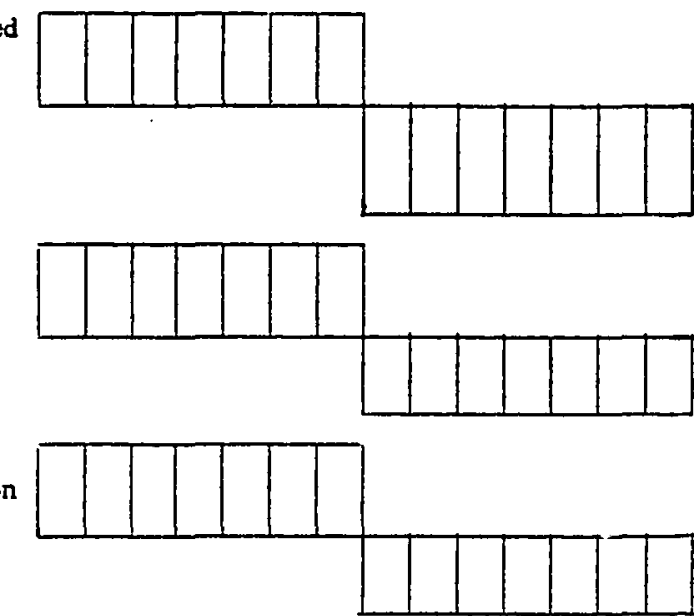

1. Substitute teachers should carry out the regular teacher's lesson plan.

In your opinion, do substitute teachers carry out the regular teacher's lesson plan?

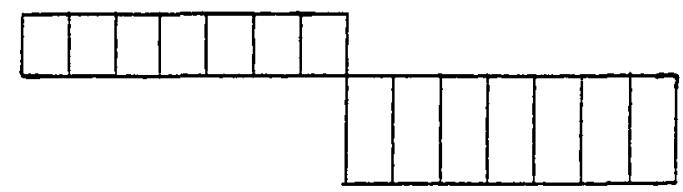

12. Substitute teachers should serve the purpose of preventing instructional loss to the students.

In your opinion, does the use of substitute teachers avoid instructional loss to the students?

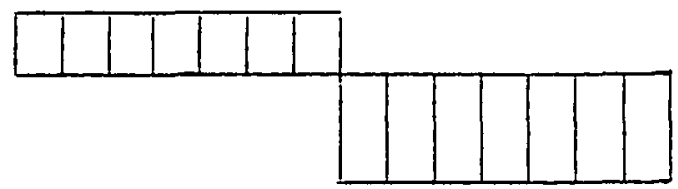

0

13. Substitute teachers' effectiveness should be measured by the extent to which they carry on the regular teacher's lesson plans.

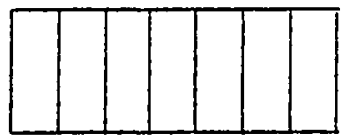




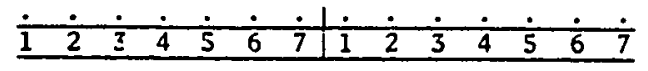

Are substitute teachers' evaluated on their effectiveness of carrying out the regular teacher's lesson plan?

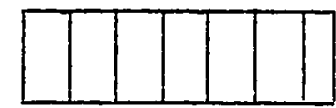

14. Substitute teacher's effectiveness should be determined by the length of notice they receive to report for an assignment.

Are substitute teachers evaluated on the basis of the lenith of time they get to report for an assignment?

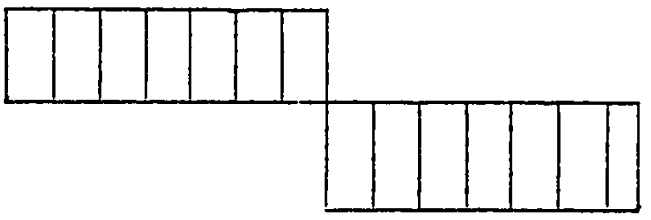

15. The amount and quality of information left for the substitute teacher's guidance should be taken into account when evaluating the substitute teacher's performance. (e.g. information about student behavior, materials and equipment, course goals and objectives)

Are the amount and quality of information taken into account when evaluating the substitute teacher?

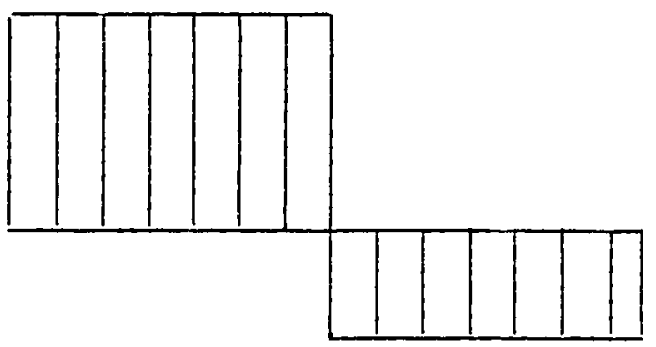

16. Substitute teachers who are given assignments in their certified fields should be effective in the classroom.

Are substitute teachers more effective when given assignments in their fields of certification?

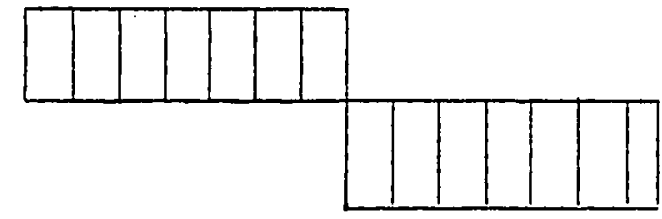

17. A favorable climate for learning should exist in the classroom if substitute teachers are to be effective.

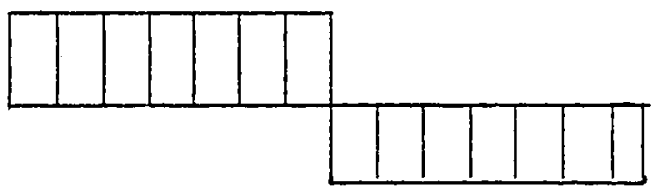
exist in the classroon?

18. The substitute teacher should be responsible for creating his/her own favorable learning environment in the classroom.

Does the substitute teacher create a favorable learning environment in the classroom?

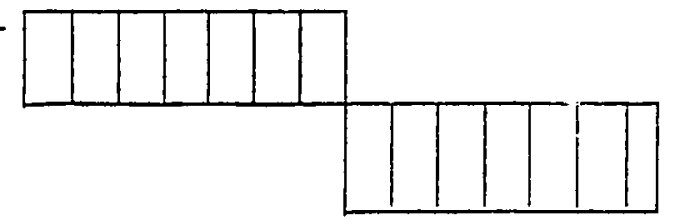

19. Substitute teachers should be effective educators.

Are substitute teachers effective educators?

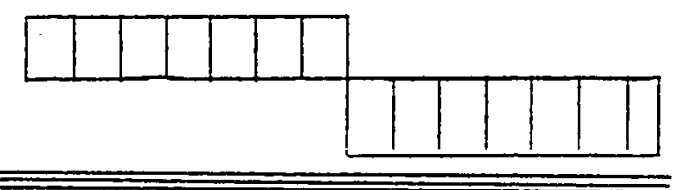




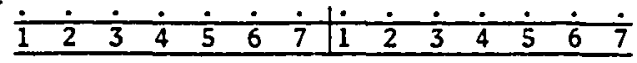

20. Substitute teachers should be encouraged to do creative work (as opposed to busy work).

To what extent are substitute teachers encouraged to da creative work?

21. Substitute teachers should be supervised in anticipation of possible full-time service.

To what extent are substitute teachers supervised and evaluated in anticipation of full-time service?

22. Substitute teachers should be included in the mainstream of school activities staff meetings, ball games, etc.

Are substitute teachers made a part of such activities?

23. Substitute teachers should be informed by the school district of professional growth opportunities to the same extent that regular teachers are.

Do substitute teachers receive this type of information from the district?
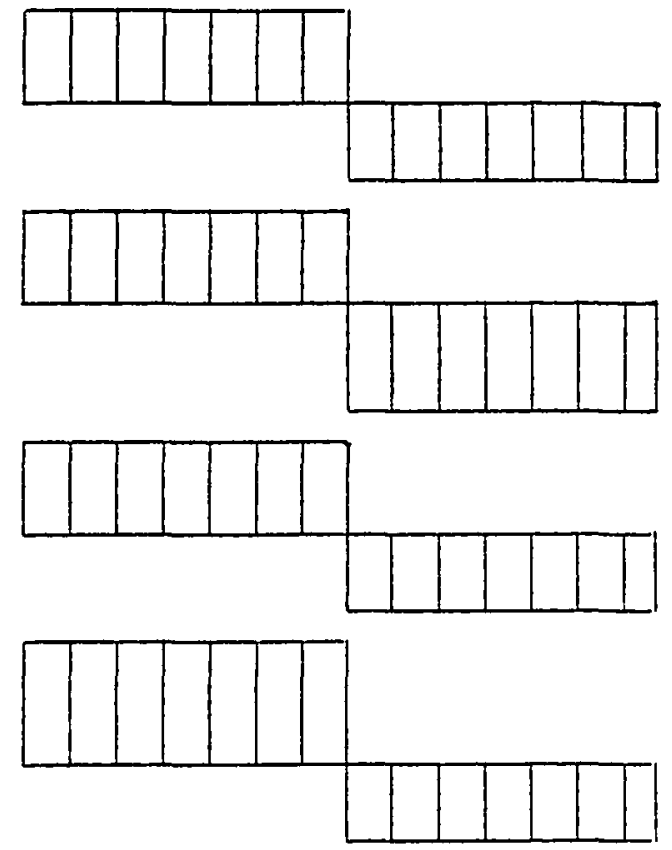

24. Substitute teachers should be informed by the school district of changes in the law affecting education to the same extent that regular teachers are.

Do substitute teachers receive this type of information from the district?

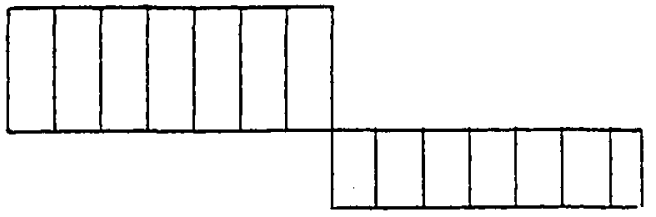

25. Substitute teachers should be encouraged to buy into the teachers' retirement fund. Do substitute teachers receive such encouragement?

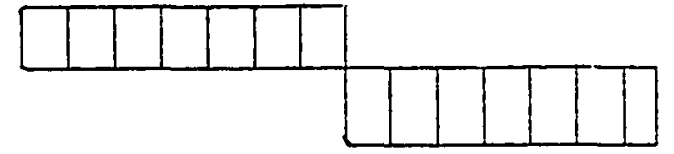

26. Substitute teachers should have collective bargaining representation.

Do substitute teachers have this representation?

27. Substitute teachers should be advised to work for a period of time long enough to discourage the receipt of unenployment compensation.
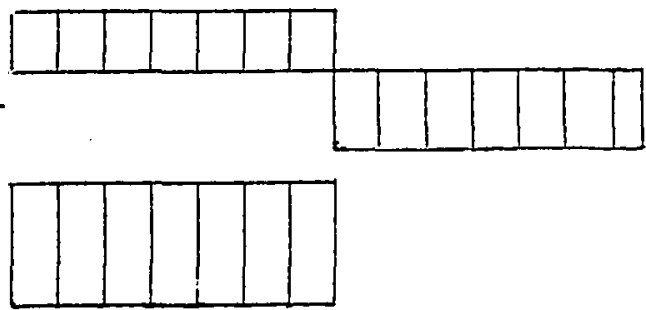


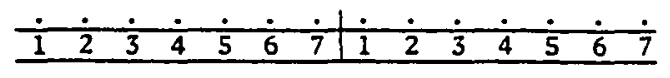

Is such advise given by the district?

28. Administrators should be made responsible for improving substitute teachers' performance.

Do administrators try to improve substitute teachers' performance?

29. The school district's policies and practices should be influential in determining substitute teacher's performance.

Are the current district policies and practices influential in determining substitute teachers' performance?

30. The school district should use building faculty members as substitute teachers. (e.g. teachers using planning time to cover for other teachers, combine classes, use non-teaching certified personnel)

Is this system of substituting used in the district?

31. Given the financial strains of the district, arrangements should be made to monitor students without the service of a substitute teacher.

Is this method of monitoring students practiced in the district?

32. When the regular teacher is absent, grieater use should be made of the library and/or resource centers without the service of a substitute teacher.

Is such use now made of the library and resource centers?

33. The administrator and regular teacher should be responsible for creating a favorable learning environment in the classroom.

Do administrators and regular teachers create such an environment?

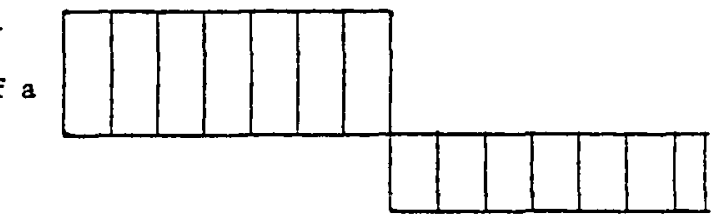

. In order to objectively evaluate substitute teachers, an in-building substitute teacher program should be initiated.
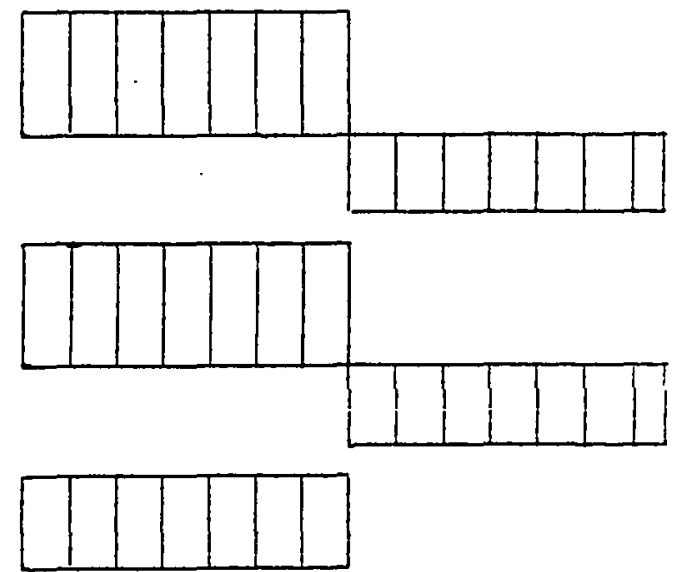


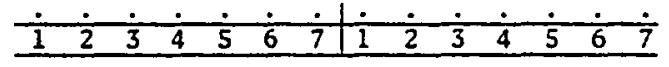

Does the district have in-building arrangements of this kind?

35. In order to administer the substitute teacher services effectively, the school district should use a centralized system. Does the school district now use a centralized system effectively?
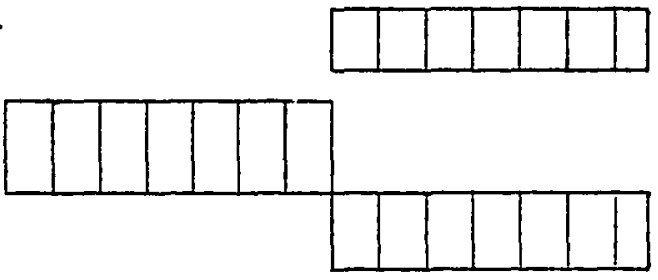

THA N K YOU! 
APPENDIX E

IETTER OF REMINDER TO EDUCATORS

WHO DID NOT REIURN QUESTIONNAIRE WITHIN TWO WEEKS 
June 14, 1982

Dear ___

You have probably forgotten to send in your questionnaire on substitute teachers that was sent to you two weeks ago. However, there is still time to do so.

If you need another questionnaire, please phone me at 288-3900.

Please disregard this notice if you have already completed and returned the questionnaire.

Thank you,

C ic. $4, i-j$ i...

C. $\{$ Jack Ryan 
APPENDIX $F$

IETTER OF INTRODUCTION TO THE PORTIAND PUBLIC SCHOOLS 
PORTLAND PUBLIC SCHOOLS

631 Northeast Clackamas Street / Pordand, Oregon 97208

Phone (503) 234-3392

Mailing Address: P. O. Box 3107

OFFICE OF THE SUPERINTENDENT
Robert W. Blancha:d Superintendent

Doneld D. H.Elroy Deputy Superintendens

To Whom It May Concern:

I am writing this letter to introduce Castilla Jack Ryan who is an employee of the Portland Public Schools. He is currently doing research on the impact of substitute teaching on education. I am sure that this is a topic that is of interest to you and is one that is of importance to our profession.

I hope that you will give Mr. Ryan every assistance as he proceeds in his collection of data for this study. He will be most appreciative of your help and will be glad to share his findings with you.

Your courtesies to Mr. Ryan are very much appreciated.

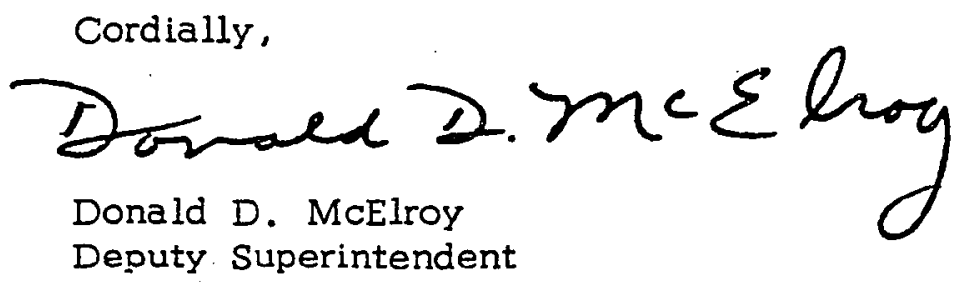

DDMC

shw 
APPENDIX G

LETTER FROM PORTLAND PUBLIC SCHOOLS ENDORSING THE STUDY 
May 14, 1982

To Whom It May Concern:

I have reviewed with Mr. C. Jack Ryan an inquiry form relating to substitute teaching that he plans to use in connection with his doctoral dissertation. I believe the questionnaire will provide useful information to the District and profession regarding perceptions about substitute policies and practices and recommend cooperating with Mr. Ryan in administering the questionnaire to administrators, teachers, and substitute teachers.

$$
\begin{aligned}
& \text { Sincerely, } \\
& \text { Vueton w. Dchersy } \\
& \text { Victor } w \text {. Doherty } \\
& \text { Assistant Superintendent } \\
& \text { Evaluation }
\end{aligned}
$$

VWD/ams 